\title{
Time-resolved surface pressure and model deformation measurements in an industrial transonic wind tunnel
}

DOI:

10.2514/6.2019-2905

\section{Document Version}

Accepted author manuscript

Link to publication record in Manchester Research Explorer

\section{Citation for published version (APA):}

Davidson, T. S., Stokes, N. P., Roberts, D. A., \& Quinn, M. K. (2019). Time-resolved surface pressure and model deformation measurements in an industrial transonic wind tunnel. In AIAA Aviation 2019 Forum https://doi.org/10.2514/6.2019-2905

\section{Published in:}

AIAA Aviation 2019 Forum

\section{Citing this paper}

Please note that where the full-text provided on Manchester Research Explorer is the Author Accepted Manuscript or Proof version this may differ from the final Published version. If citing, it is advised that you check and use the publisher's definitive version.

\section{General rights}

Copyright and moral rights for the publications made accessible in the Research Explorer are retained by the authors and/or other copyright owners and it is a condition of accessing publications that users recognise and abide by the legal requirements associated with these rights.

\section{Takedown policy}

If you believe that this document breaches copyright please refer to the University of Manchester's Takedown Procedures [http://man.ac.uk/04Y6Bo] or contact uml.scholarlycommunications@manchester.ac.uk providing relevant details, so we can investigate your claim.

\section{OPEN ACCESS}




\title{
Time-resolved surface pressure and model deformation measurements in an industrial transonic wind tunnel
}

\author{
Todd S. C. Davidson, ${ }^{1}$ Neil P. Stokes ${ }^{2}$, David A. Roberts ${ }^{3}$ \\ Aircraft Research Association Limited, Bedford, MK41 7PF, United Kingdom \\ Mark K. Quinn ${ }^{4}$ \\ University of Manchester, Manchester, M13 9PL, United Kingdom
}

\begin{abstract}
This paper presents the advanced optical diagnostics techniques deployed in a recent proving test of the Gust Generation Facility in the ARA TWT. A porous polymer-ceramic pressure-sensitive paint was used to record the pressure on both the upper and lower surfaces of ARA's reference civil half-model as a gust passed, and stereographic digital image correlation was used to obtain the corresponding structural response. The difficulties of applying these methods in an industrial facility is addressed, along with an overview of the results acquired and a discussion of the ways in which such data can be used to validate fluidstructure interaction simulations and to improve aircraft design.
\end{abstract}

\section{Nomenclature}

$\begin{array}{ll}A R A & =\text { Aircraft Research Association, Ltd. } \\ C F D & =\text { computational fluid dynamics } \\ C_{p} & =\text { pressure coefficient } \\ D I C & =\text { digital image correlation } \\ D P S P & =\text { dynamic pressure-sensitive paint } \\ D M D M & =\text { dynamic model deformation measurements } \\ I & =\text { image intensity } \\ I R(T) & =\text { infra-red (thermography) } \\ L E D & =\text { light-emitting diode } \\ M & =\text { Mach number } \\ p & =\text { static pressure } \\ r e f & =\text { reference condition } \\ T & =\text { temperature } \\ T W T & =\text { Transonic Wind Tunnel } \\ U V & =\text { ultra-violet } \\ \alpha & =\text { model incidence } \\ \alpha_{g} & =\text { peak gust amplitude incidence }\end{array}$

\section{Introduction}

As the capabilities and accuracy of computational fluid dynamics have improved over the decades, traditional wind tunnel testing has often come to be seen at worst as expensive and unnecessary or at best as a simple validation tool. However, there are still areas where simulations are known to struggle to perform, and as such, there is a real push for experimentalists to be able to acquire data with greater speed, resolution and precision, both to improve our understanding of complex flow physics and to inform the next generation of modelling advances.

The development of the techniques that lead to these insights is usually the province of academic research institutions, where basic principles can be demonstrated and the measurements' capabilities and limitations can be

\footnotetext{
${ }^{1}$ Optical Diagnostics Development Engineer, Aerodynamics Capability Department; also Knowledge Transfer Partnership Associate at the University of Manchester; AIAA Member

${ }^{2}$ Optical Measurement Systems Manager, Experimental Aerodynamics Department

3 Technical Team Leader, Aerodynamics Capability Department; corresponding author: droberts@ara.co.uk

${ }^{4}$ Lecturer in Aerospace Engineering, School of Mechanical, Aeronautical and Civil Engineering; AIAA Member
} 
determined in comparatively simple laboratory settings. In recent years, there has been increasing demand for these proven methods to be adapted for use in industrial tunnels, which adds an additional layer of difficulty. These challenges can be environmental, such as increased temperature, pressure ranges and vibration; technical, such as greater distances, volumes, speeds and reduced optical access; and economical, such as a premium on installation time and a push for reduced time-to-data. Also of great interest, in both academic and industrial facilities, is the quantification of uncertainties at all stages from set-up and acquisition through to processing and analysis.

This paper will address some of these issues in the context of a recent experiment conducted during proving tests of the Gust Generation Facility in ARA's Transonic Wind Tunnel (TWT). Both Dynamic Pressure-Sensitive Paint (DPSP) and Dynamic Model Deformation Measurements (DMDM) were deployed to capture the unsteady variation of surface pressure and the induced structural deformation of the ARA reference civil half-model at conditions around cruise during the passage of a transonic gust.

\section{Experimental facility}

\section{A. ARA's Transonic Wind Tunnel}

The ARA TWT is a closed-return circuit (Figure 1) with a working section of $2.8 \mathrm{~m} \mathrm{x} 2.4 \mathrm{~m} \mathrm{(9} \mathrm{ft} \mathrm{x} 8 \mathrm{ft}$ ), a total pressure range of 0.8 to 1.2 bar and a Mach number range of 0.2 to 1.4. The working section has porous walls to reduce blockage/confinement effects, with a maximum porosity of $22 \%$. Models are usually either full span and mounted on a rear sting (Figure 2) or floor-mounted half-span (Figure 3).

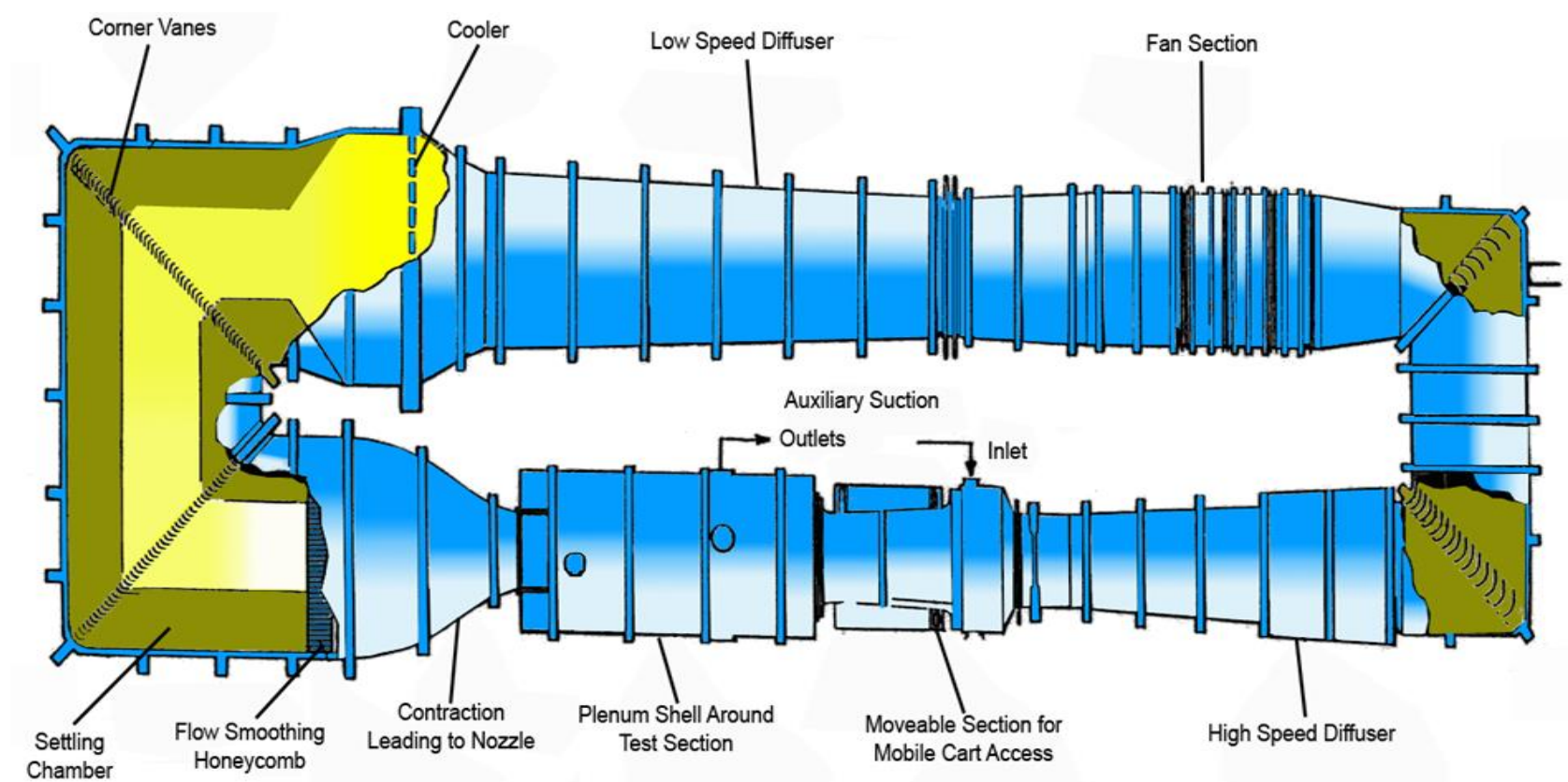

Figure 1: Schematic of the ARA TWT.

Unlike many other wind tunnels, the ARA TWT has no windows for optical access. Instead, there are a number of holes cut in each of the tunnel walls (visible, for instance, on the left-hand side of Figure 2), behind which cameras and lights can be mounted to the stringers that give the walls their rigidity. Naturally, all models are different shapes and sizes and so equipment can rarely be ideally positioned, meaning that flexibility and creativity are vital for capturing the best possible data. When not in use, the holes are fitted with cover plates to maintain the porosity, although lift and drag measurements taken with and without covers show no significant effects. [1]

As a commercial facility, time is always a critical factor on the cost of testing, and this includes the time required to install optical measurement equipment. This means that setting up for a technique needs to be as rehearsed and smooth as possible, which is not always easy when carrying heavy, delicate hardware through hot, cramped access routes between the outer shell of the pressure vessel and the walls of the working section. Additionally, due to the high levels of artificial optical radiation involved during alignment and check-out (whether in the form of laser light or from UV LEDs), not all tasks can be performed in parallel with other test preparation activities meaning there is often a long setup time required for and hence high upfront cost to optical measurements. This can make short test campaigns can seem expensive from a price-per-data-point perspective. However, optical measurements provide 
greater insight into the behavior of the flow when compared with traditional point measurement techniques. When viewed in this light, optical techniques can provide excellent value for in-depth information on aerodynamic and structural features which could not have been captured traditionally.

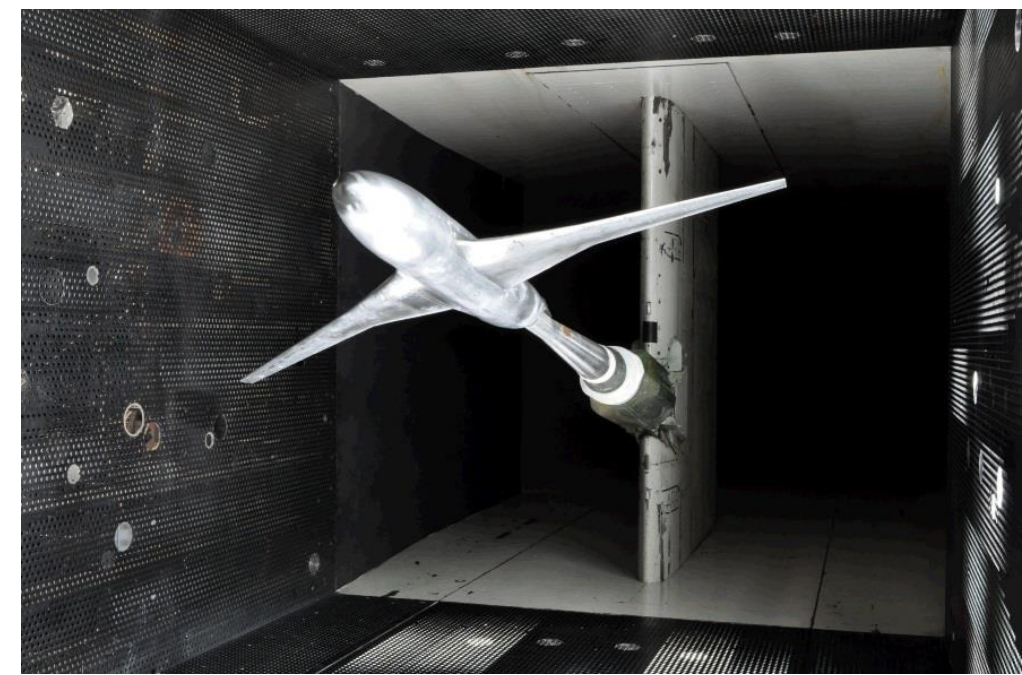

Figure 2: ARA's sting-mounted full-span civil reference model in the TWT working section.

\section{B. Gust Generation Facility}

One particular area where current industrial CFD and experimental capabilities struggle is in off-design conditions, where dynamic phenomena play an important role and unsteady loads are key. Currently, performance assessment of aircraft dynamic behaviour at the early design stages, including loading due to gusts, uses a mix of simple numerical models and historical results. This process is not adequate for innovative aircraft configurations and there is a dearth of good quality experimental data for code validation, as well as design and certification purposes, on the aerodynamic response to dynamic conditions. The fact that gust response loads are a significant part of the overall critical load cases for an aircraft adds emphasis to the requirement for new capabilities. The absence of appropriate tools drives designs to be overly conservative, particularly structurally, implying additional weight and, hence, environmental impact through excessive fuel burn and resulting emissions.

ARA began a programme of work in 2012 to invent, design and manufacture an experimental apparatus for gust simulation in the TWT through a UK government-funded project entitled "Aircraft Loads Alleviation Technology". The chosen solution was based on controlled, directed trailing-edge Coanda-effect blowing from two vertical vanes situated in the contraction section of the TWT. A pulse of high-pressure air is directed through a rearward slot on either the port or starboard side of the vanes to create a time-varying bulk axial swirl in the working section, which influences a floor-mounted half-model as a change in oncoming flow incidence. The vanes each have five reservoirs along their height with a large number of solenoid valves to allow fine control of the gust characteristics - varying the pressure in each chamber and the opening timings of the valves permits gusts of different durations, temporal profiles and span-wise distributions - and a paddle mechanism to select gust direction.

The first version of the Gust Generation Facility was tested in March 2014 and the concept was successfully proven. [2] Further tests to explore the capabilities and improve the control system were conducted in 2017. The programme - including the optical measurement techniques discussed here - consisted of a range of free-stream Mach numbers from 0.5 to 0.82 , model angles-of-attack from 0 to 3 degrees, and gust durations from 10 to $100 \mathrm{~ms}$, all with a '1-cosine' profile as specified in the CS-25 airworthiness certification specifications. [3] It is believed that this facility is the only industrialised one of its kind in the world.

\section{Reference civil half-model}

ARA's reference civil half-model has a wing-fuselage configuration as shown in Figure 3 and was mounted on a 5-component balance on ARA's half-cart turntable. Transition was fixed at 15\% chord on the upper surface and 5\% on the lower surface, and just aft of the nose on the fuselage. The wing is furnished with 274 static pressure tappings, with 23 unsteady pressure transducers in the outboard upper surface. The model also features 8 accelerometers to measure structural vibrations and a wing-root strain gauge. 

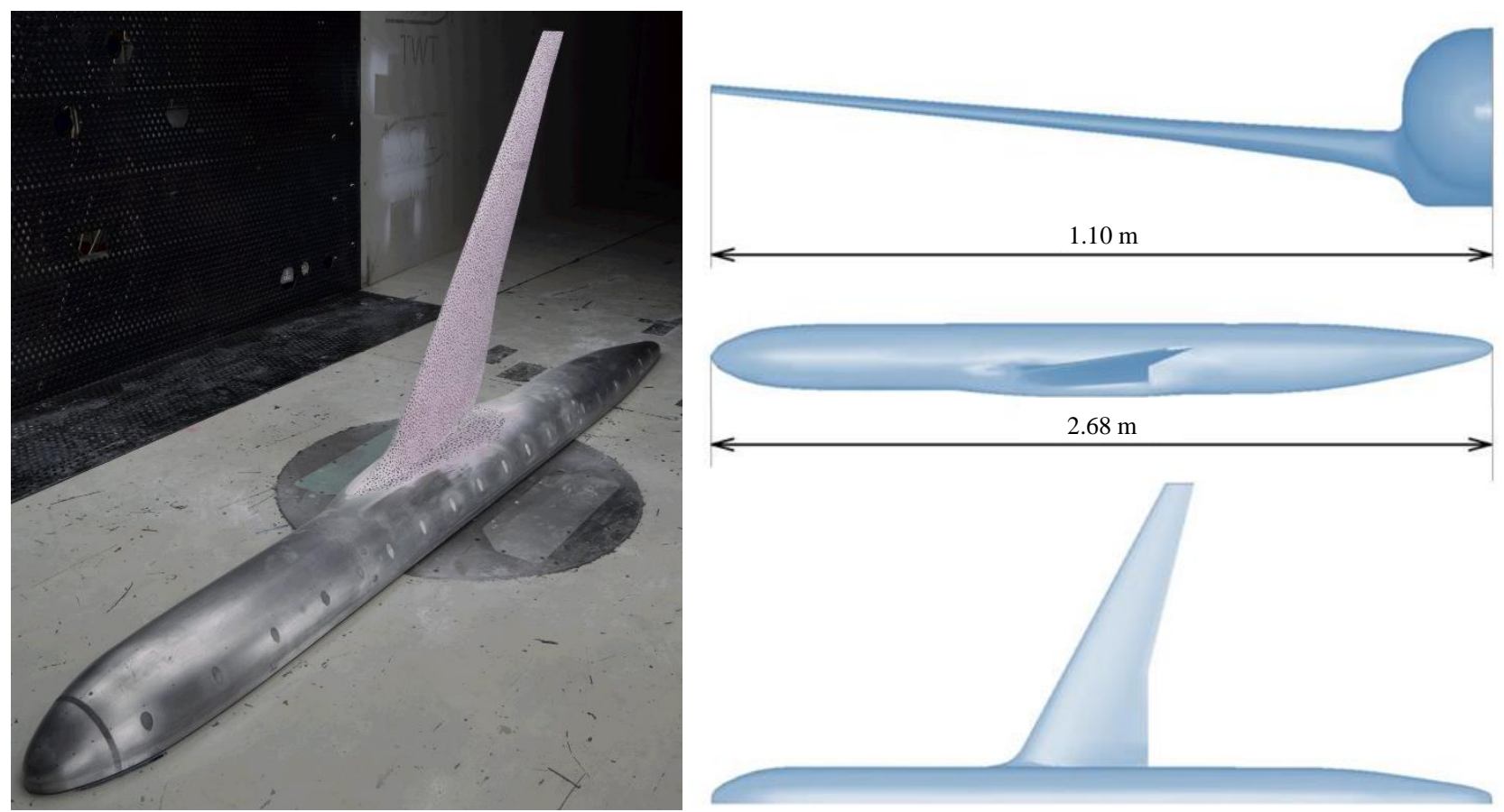

Figure 3: ARA's civil reference half-model: (a) in tunnel with DPSP and MDM dots; (b) general schematic.

\section{Dynamic pressure-sensitive paint measurements}

\section{A. Theory \& implementation}

Pressure-sensitive paints are sensitive to the local static pressure through a process called oxygen quenching. When a luminescent molecule in the paint absorbs a photon of the correct wavelength, the molecule transitions to an excited energy state. The molecule then has to recover to the ground state through the emission of a photon at longer wavelength compared to the absorbed photon (Figure 4). The rate at which this process occurs is proportional to the local partial pressure of oxygen, and so the output intensity of the paint is related to the static pressure over its surface. To account for inconsistencies in illumination and paint surface finish over the model the pressure is calibrated against the ratio of the wind-on and a wind-off reference image, where the model is at a uniform known pressure. [4]

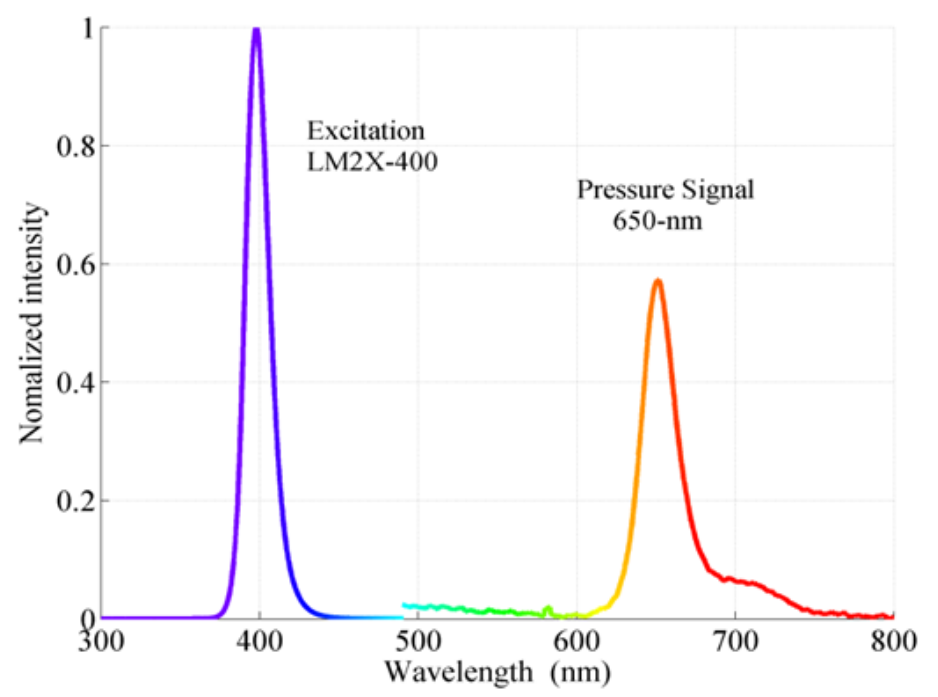

Figure 4: Excitation and response wavelengths for DPSP used at ARA.

Typically, the luminescent molecule, known as a luminophore, is incorporated into an oxygen-permeable binder material to allow the coating to adhere to a model surface. This standard formulation has the disadvantage of slow response to changes in pressure due to the finite time for oxygen diffusion through the paint coating. To achieve a 
faster response to changes in pressure, the luminophore can be sprayed directly onto a porous binder layer. The porosity of this layer allows for oxygen to quickly diffuse into the paint layer enabling a faster response to changes in the local surface pressure. [4]

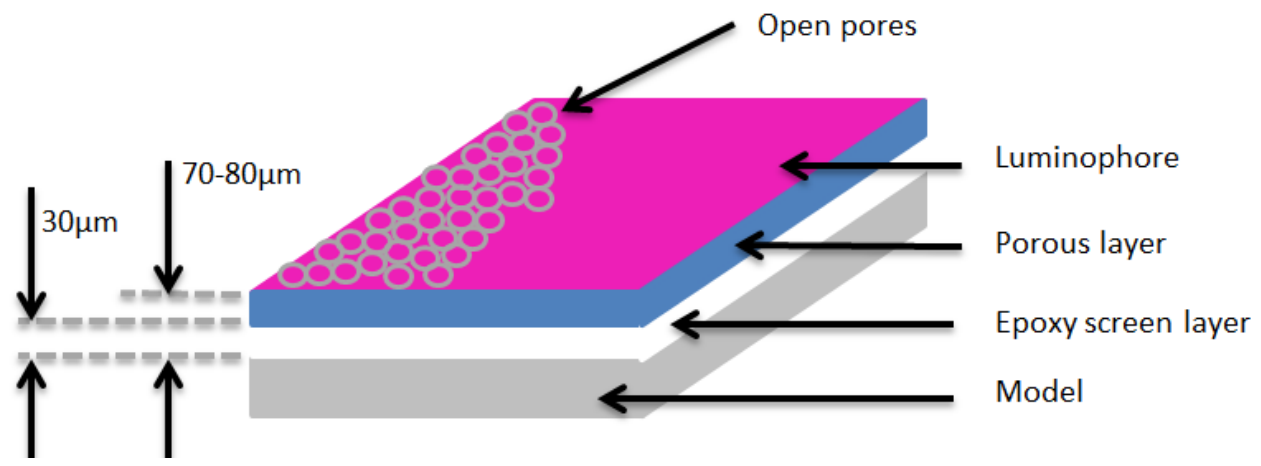

Figure 5: DPSP application and typical component thicknesses.

One downside of this approach is an increased sensitivity of the output light levels to temperature, due to the application method of the paint exposing the luminophore directly. This can be seen in Figure 6, where results from a calibration chamber are presented. A paint sample is subjected to an independently controlled pressure and temperature, and then illuminated and imaged as if applied to a wind tunnel model. It is clear that varying the temperature of the sample has a large impact on the observed intensity ratio - according to the data sheet, $3.6 \% / \mathrm{K}$, as compared to $0.6 \% / \mathrm{K}$ for the standard lifetime PSP used at ARA.

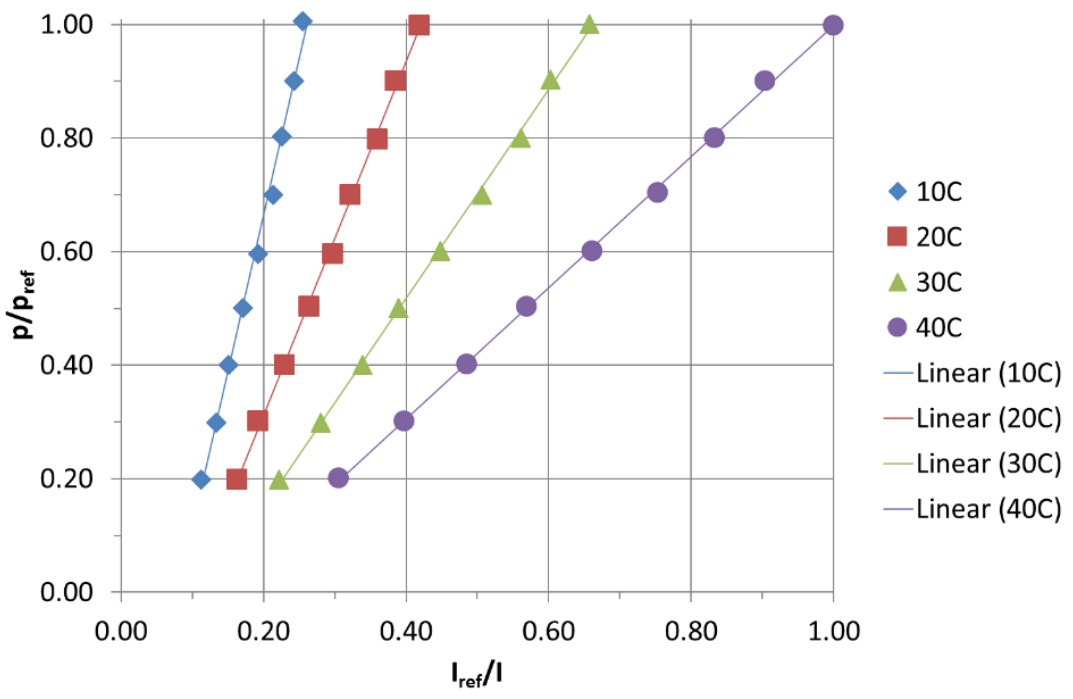

Figure 6: Calibration chamber results for a DPSP sample (reference conditions: 1 bar, $40{ }^{\circ} \mathrm{C}$ ).

ARA uses a fast-response pressure-sensitive paint produced by Innovative Scientific Solutions Incorporated. This is a platinum tetra(pentafluorophenyl)-porphine-based porous polymer-ceramic formulation which has been shown to have a frequency response of greater than $20 \mathrm{kHz}$. [5] The model is first prepared with a white epoxy screen layer, which serves two main purposes: firstly to provide a primer over the metal model surface which allows the porous coating to adhere to the model, and secondly to provide thermal insulation between the luminophore and the model surface. Thermal insulation is important as all PSPs are also sensitive to temperature and model features that have differing thermal properties, such as tube runs or material changes, can be identified in the paint output, creating errors in the pressure data. This layer is typically around $30 \mu \mathrm{m}$ thick, with a roughness of around $1 \mu \mathrm{m} \mathrm{Ra}$, and was applied in the ARA spray booth and then baked at $65^{\circ} \mathrm{C}$ for 1 hour to remove any solvent residue. The porous layer was then mixed and applied to both the upper and lower surfaces of the wing, and the model again baked in the curing oven. The sensitive layer was not applied until the model was installed in the TWT as it degrades rapidly under UV illumination. The total paint thickness is typically around 70-80 $\mu \mathrm{m}$ (Figure 5). 


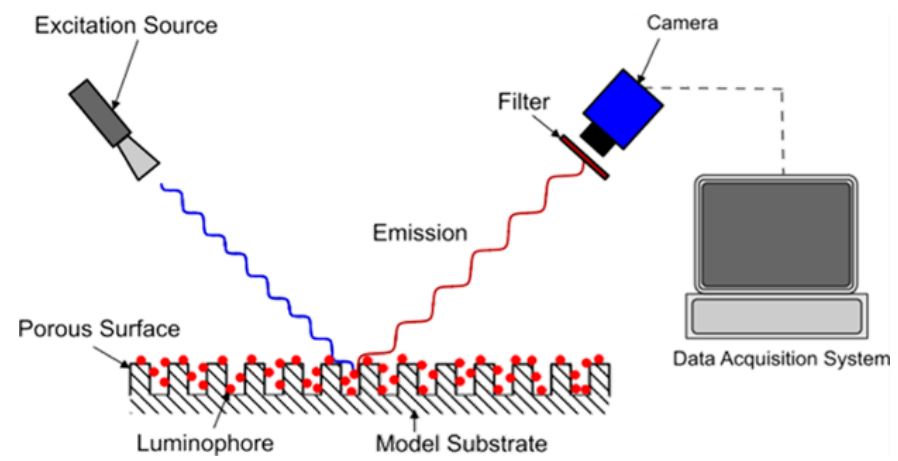

Figure 7: Typical DPSP acquisition setup. [6]

Three ISSI LM2XX-DM-400 $12 \mathrm{~W}$ continuous UV lamps illuminated the lower surface, with four used on the upper surface. Lower surface images were acquired with a Phantom v1611 high speed camera installed in the port wall, and upper surface images were acquired with a Phantom v1610 high speed camera installed in the starboard wall, both with $35 \mathrm{~mm}$ focal length lenses and $600 \mathrm{~nm}$ high-pass ('red') optical filters to block out the incident UV illumination. The cameras, lamps and gusts were all triggered by the Gust Generation Facility control system to ensure appropriate timings. 1,375 images were captured for each data point at an acquisition rate of 2,000 frames per second.

In order to convert the raw images into pressure data, the wind-on and wind-off frames are first aligned to remove the effects of camera vibration before the ratio is taken. The intensity ratio at each of the static pressure taps is then extracted, averaged through time and compared to the measured pressure to generate a calibration curve (Figure 8). This calibration is applied to each frame of each data point to create a full surface pressure map through time of each side of the wing.

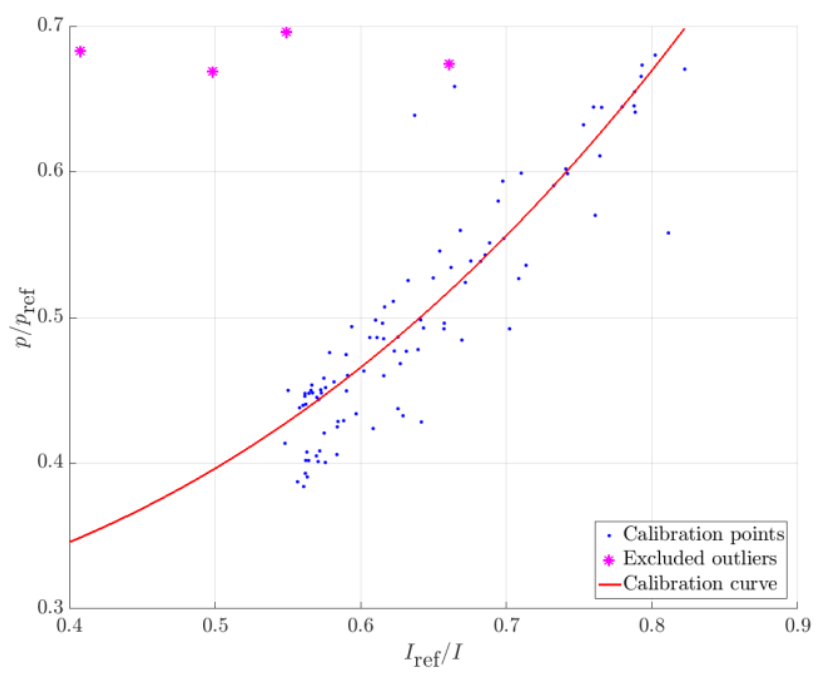

Figure 8: Example upper surface DPSP calibration.

\section{B. Results \& discussion}

Sample DPSP snapshots from the upper surface for two different gust lengths are shown in Figure 9 and Figure 10, illustrating the mean pressure field, the surface pressure at the gust peaks, and the difference due to the gust. The peak pressure difference is greater with the shorter gust than the longer, perhaps due to the faster rate of change allowing less time for the flow field to adjust. Figure 11 shows the equivalent figures for the pressure side of the wing - by comparing this with Figure 10 and averaging the imaged pressure fields over each surface area, a crude estimate of the gust loading can be prepared. A pre-gust spatial mean upper \& lower surface $C_{p}$ of $-0.35 \&-0.05$ compared to peaks at the gust of $-0.39 \&-0.03$ give a temporary increase in lift of $20 \%$. To improve on these simple estimates and gain greater understanding of the flow physics, ARA is investing in extending its mapping capabilities - for the standard lifetime PSP offering, images are semi-automatically mapped to a CAD mesh of the wind tunnel model, from which loads can be calculated with reasonable accuracy. [7] By developing this method to be compatible with dynamic PSP images, real-time loads should be within reach - though with the caveat that with only two high-speed cameras, 
it will always be a challenge to obtain data on the leading and trailing edges or around more complicated wing features, and so drag measurements in particular will still present a challenge. However, an accurate estimate of the gust loading factor would be a useful enhancement to the technique.
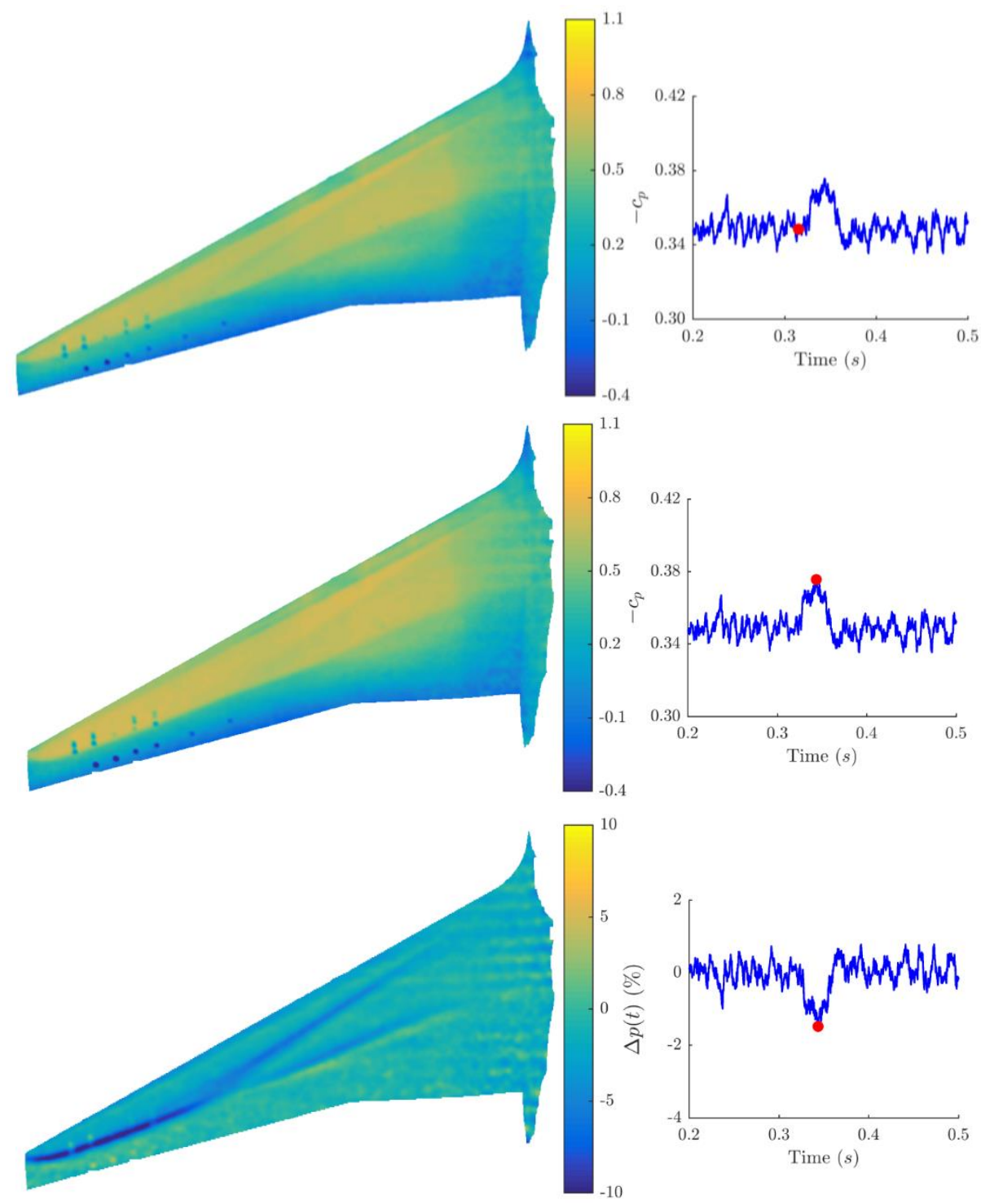

Figure 9: Snapshot images of upper surface pressure and mean pressure variation time history for a $50 \mathrm{~ms}$ gust at Mach 0.82 - top, pre-gust $\mathrm{Cp}$; middle, gust peak $\mathrm{Cp}$; bottom, gust peak pixel variation from mean. The right-hand graphs show the variation through time of the spatial mean of these quantities.

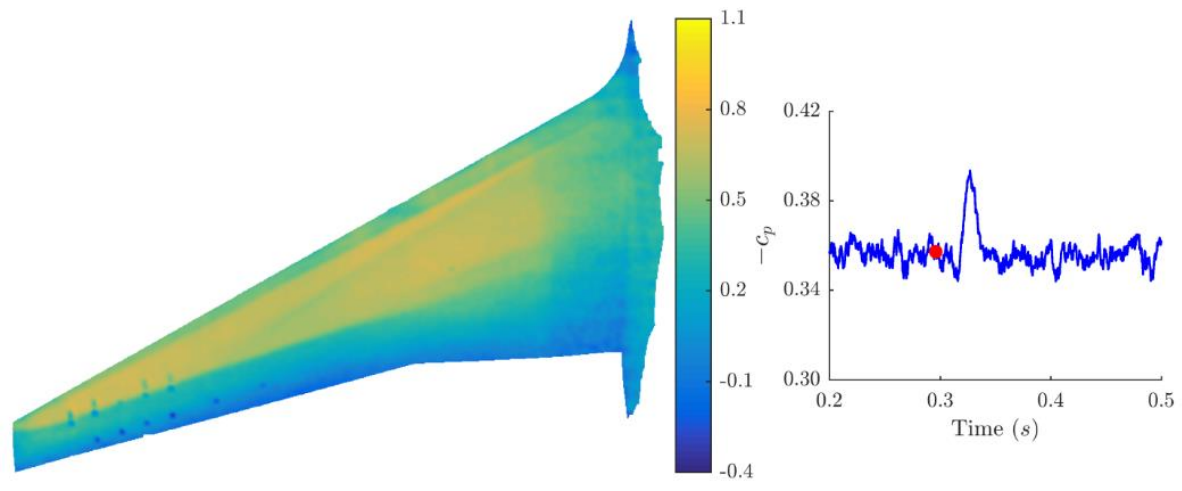



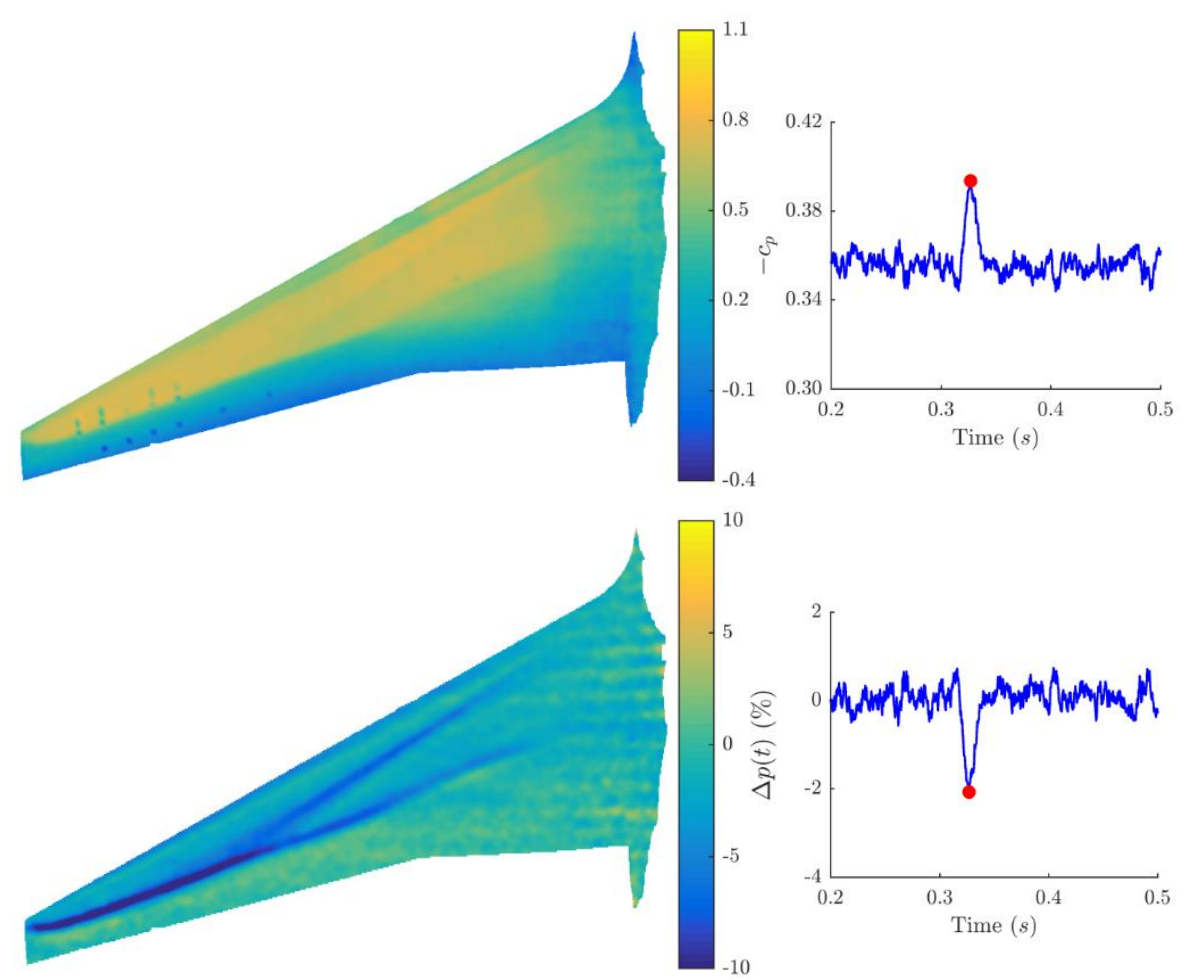

Figure 10: Snapshot images of upper surface pressure and mean pressure variation time history for a $25 \mathrm{~ms}$ gust at Mach 0.82 - top, pre-gust $\mathrm{Cp}$; middle, gust peak $\mathrm{Cp}$; bottom, gust peak pixel variation from mean.
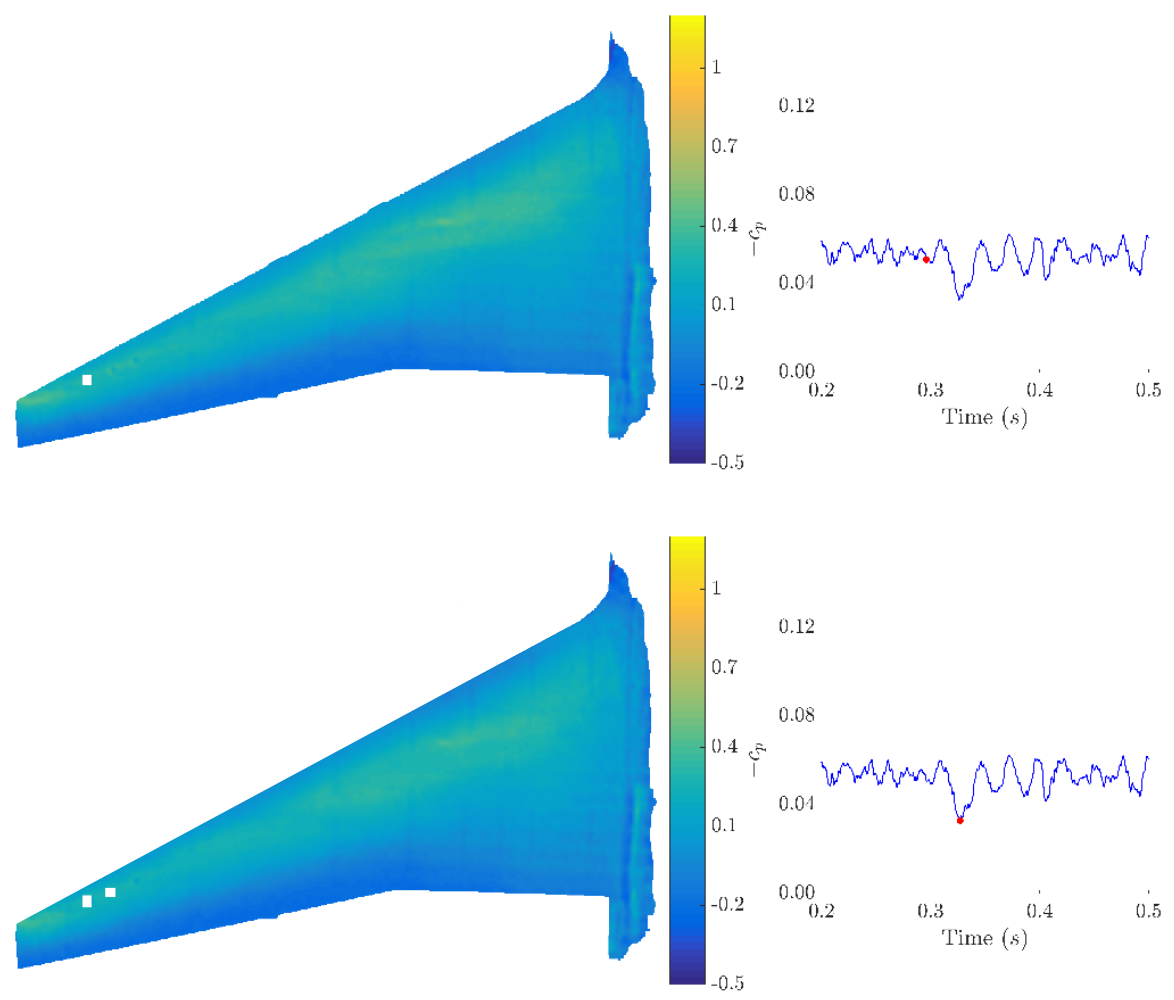

8 


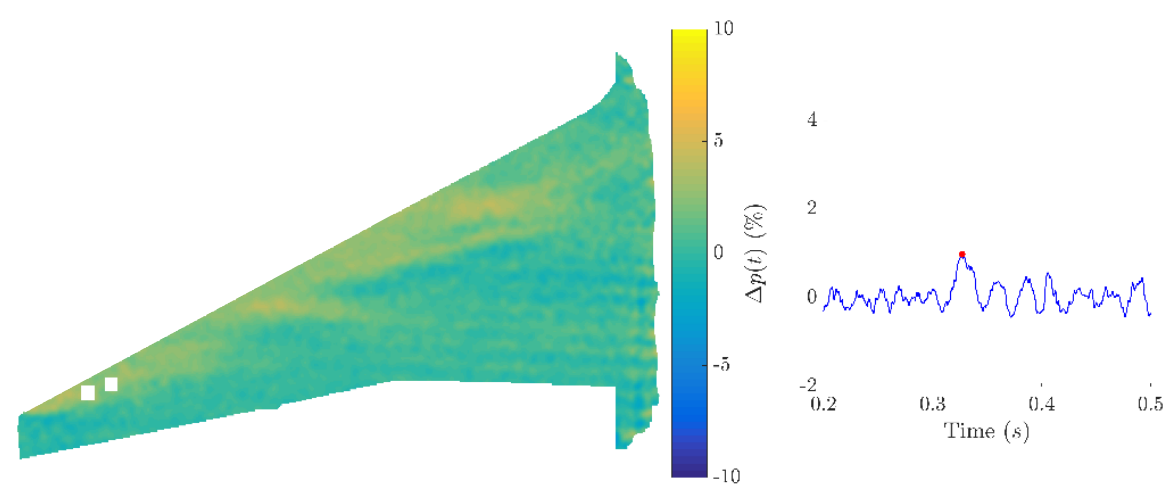

Figure 11: The lower surface pressure response to the 25 ms gust at Mach 0.82 .

The stripes visible near the wing root are a camera artefact, illustrating the difficulties of recording this kind of data even with state-of-the-art imaging equipment - camera chip noise is evident. This could be due to a number of reasons, and likely a combination of factors contribute to this. As seen in Figure 12, this area is noticeably darker, distinct from the flow. Due to the distances involved and the lack of optical access, this could simply be down to a lack of illumination, particularly so near the floor of the tunnel. However, this is true for both the wind-on \& windoff, and so should - in theory at least - ratio out, whereas it seems to manifest in the data as a region of slightly higher than expected pressure (by approximately $3 \mathrm{kPa}$ ).

Examination of the test photographs shows that this region of discrepancy seems to coincide with an area of brighter paint (Figure 13), both in the base layer and in the sense layer, and indeed paint measurements suggest this region is perhaps of the order of 10 microns thicker than the neighbouring regions. Once again, however, this should in principle ratio out, as it is an influence present in both cases.

Infrared thermography images were also acquired during the test using ARA's FLIR A655sc microbolometer IR camera. While this does not give a precise measurement of the temperature of the model as it has not been calibrated for the particular surface covering, it does give a useful indication and has been found to be welcome in diagnosing discrepancies in PSP data in the past and, hence IR images are often taken during these tests.

Figure 13(c) shows an IR image taken at the start of the experiment indicating that this root region of the wing is hotter than the rest, due to the presence of the balance in the base of the model (which is temperature-controlled to avoid the effects of thermal variations during a test). However, this does not seem to be the cause of the difference seen in the pressure field (though it may explain why the paint is thicker in this region) as Figure 14 shows the IR images taken during a wind-on acquisition and during the post-run wind-off DPSP acquisition, which is the actual sample used for the data processing for this very reason - it is known that models can undergo significant thermal variation during a run and so wind-offs are acquired shortly afterwards for all DPSP \& standard PSP tests to minimise thermal effects, and indeed run lengths are limited so that the difference between early data points and the eventual wind-offs are not too great. Figure 14(c) shows that although there clearly is a change in surface temperature, it is difficult to attribute a great impact to the balance heating. There is perhaps a $0.5 \mathrm{~K}$ difference though, which equates to a $1.8 \%$ change in intensity, or a $2.4 \%$ pressure variation, which is not significantly different to that observed.

Based on these IR observations, we can inspect the calibration curve shown earlier in more detail, which showed an r.m.s. error between the calibration points and the fitted curve of $1.8 \mathrm{kPa}$, or approximately $2 \%$ of the reference wind-off pressure. Colouring the points by chordwise position as in Figure 15 reveals the expected trend of the lowest pressures, and consequently the brightest intensities (noting that the calibration is plotted as $I_{\text {ref }} / I$ ), are seen around mid-chord. We can then instead colour the points by their spanwise position in Figure 16 to examine the thermal variation due to the balance discussed above. The calibration chamber data in Figure 6 shows that intensity increases as wind-on temperature decreases (and so $I_{\text {ref }} / I$ decreases) and so we might expect that 'blue' points corresponding to the near-root pressure taps appear further on the left than they might otherwise due to their greater temperature drop from their balance-heated state.

An anticipated fringe benefit of the improved mapping software will be the ability to also map IR images on to the mesh, and so remove some of the impact of thermal variations by including wind-on \& wind-off IRT data in the processing pipeline and correcting for these effects as appropriate. 

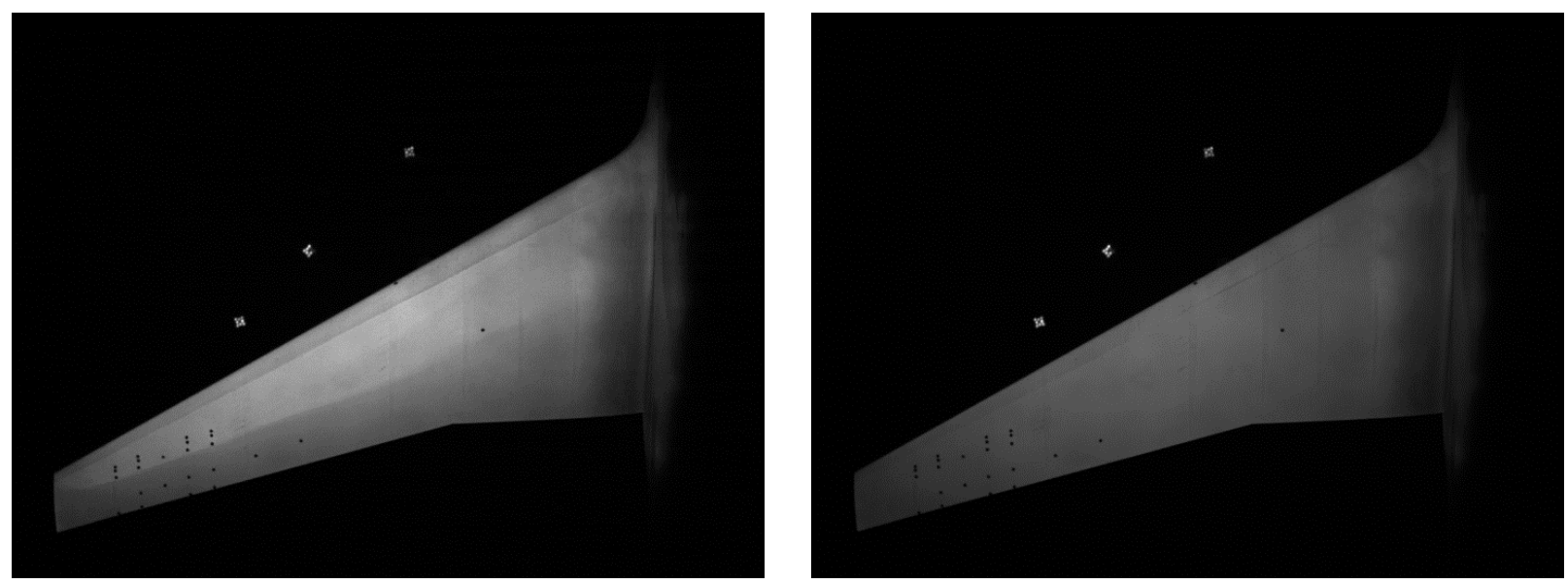

Figure 12: Raw image snapshots for the data of Figure 10: (a) wind-on; (b) wind-off.
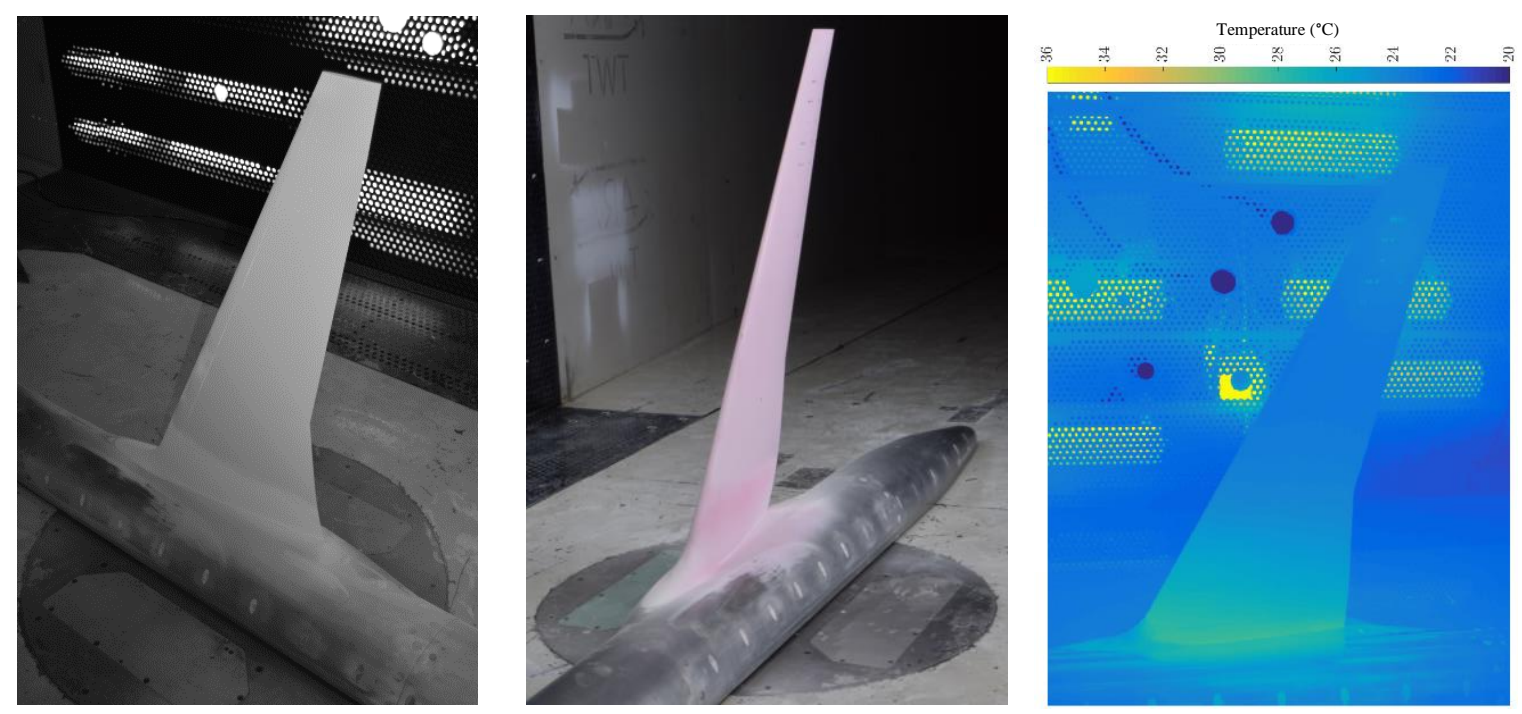

Figure 13: Photographs of paint coverage \& IR image showing balance heating.
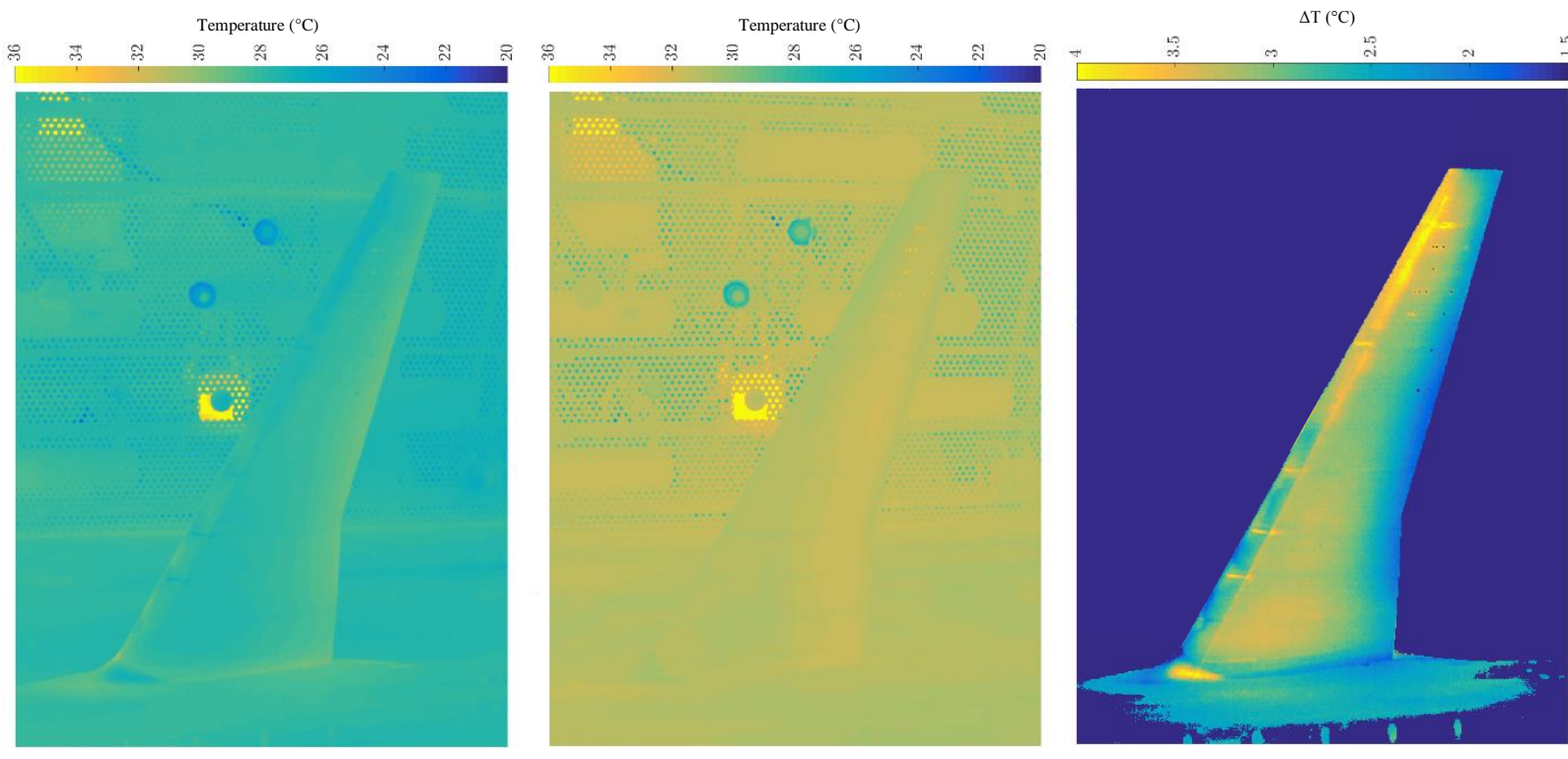

Figure 14: (a) wind-on IR image at Mach 0.7; (b) wind-off image; (c) difference. 

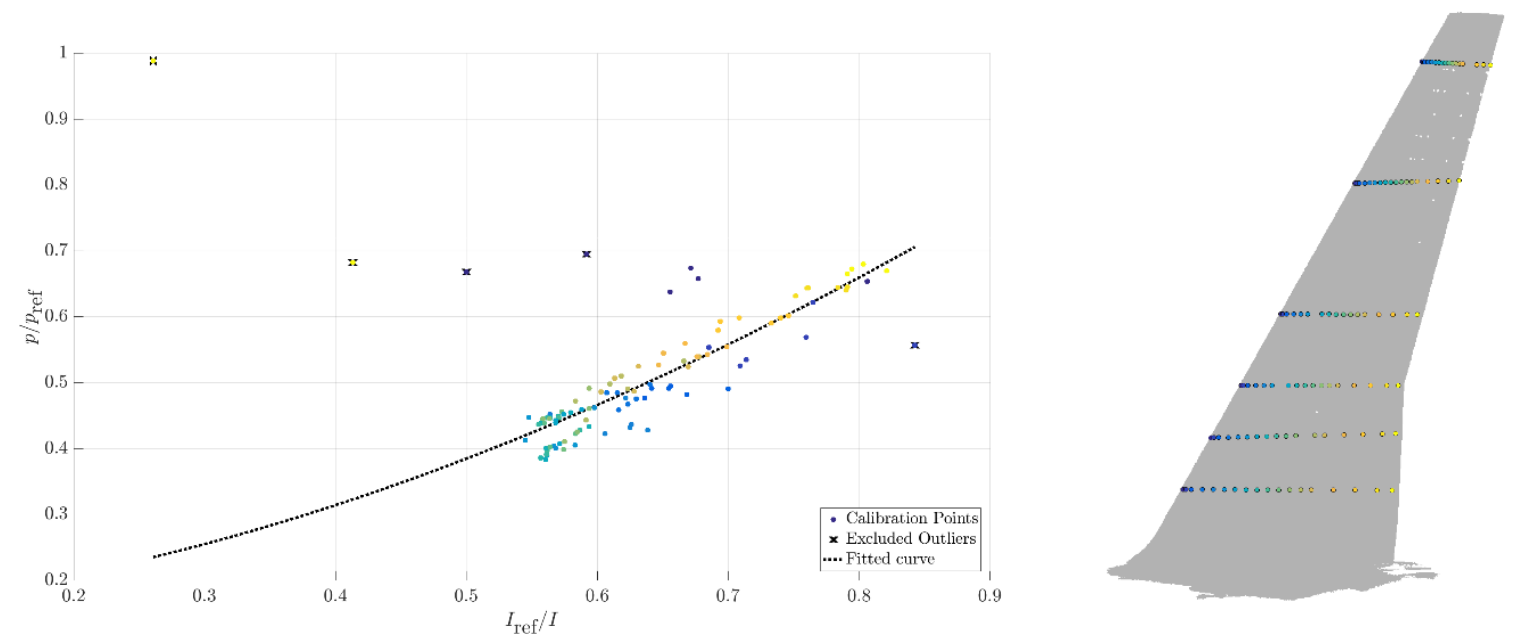

Figure 15: Calibration curve and tap locations coloured by chordwise position.
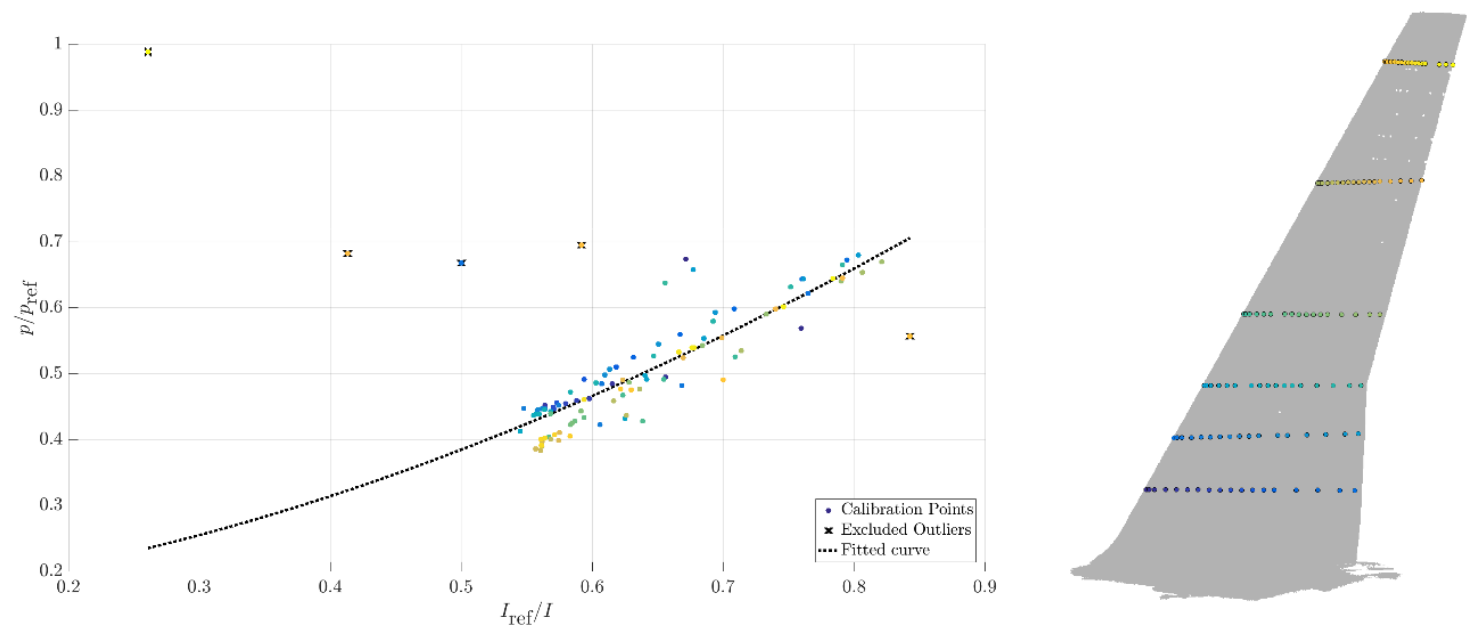

Figure 16: Calibration curve and tap locations coloured by spanwise position.

For this test, static pressure taps were used instead of fast-response transducers to calibrate the DPSP response, as this is a legacy model from a buffet onset investigation (Ref. [8]) for which the transducers are concentrated towards the trailing edge of the outboard wing sections, and so do not cover a representative pressure and temperature range. This is an acceptable approach due to the linearity of the paint's response to pressure over the nominal $<10 \mathrm{kHz}$ operating bandwidth and indeed is also a widely used method used to calibrate unsteady transducers. The unsteady pressure transducers can still be used as an independent test of the accuracy of the DPSP data, as shown in Figure 17. The relevant pressure value from the DPSP is extracted as follows (Figure 18): the approximate pixel location of each transducer is taken by identifying each one in the image; this guess is improved by employing a Hough circle detection algorithm in the surrounding area and the radius also obtained; a ring of 2 pixels is taken around this circle to avoid using the non-data regions (the transducers themselves are covered during paint spraying to avoid damage). Finally, as these regions may lie close to other features such as the trailing edge or, on other models, screw holes, model lines or distinct surfaces, a histogram is fitted to the extracted values to obtain the appropriate pressure value for comparison against the transducer measurement.

The comparison is pleasingly precise, with an r.m.s. variation of only $1.1 \mathrm{kPa}$, despite the discussed error sources here of camera vibration, paint thickness, lighting variation, temperature fluctuations and camera chip noise, suggesting a surprising resilience of the measurement technique and proving the use of DPSP in determining transient surface pressure flow fields. 

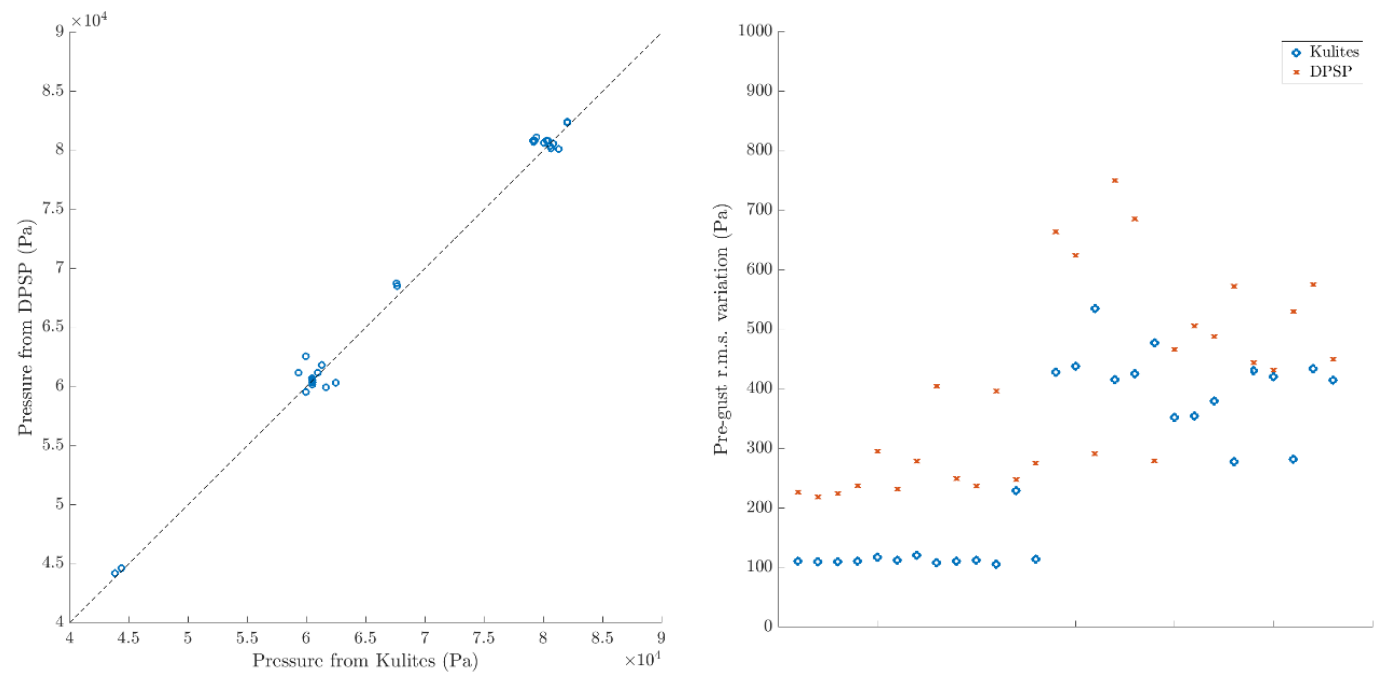

Figure 17: DPSP data vs. measured pressure from fast-response transducers.
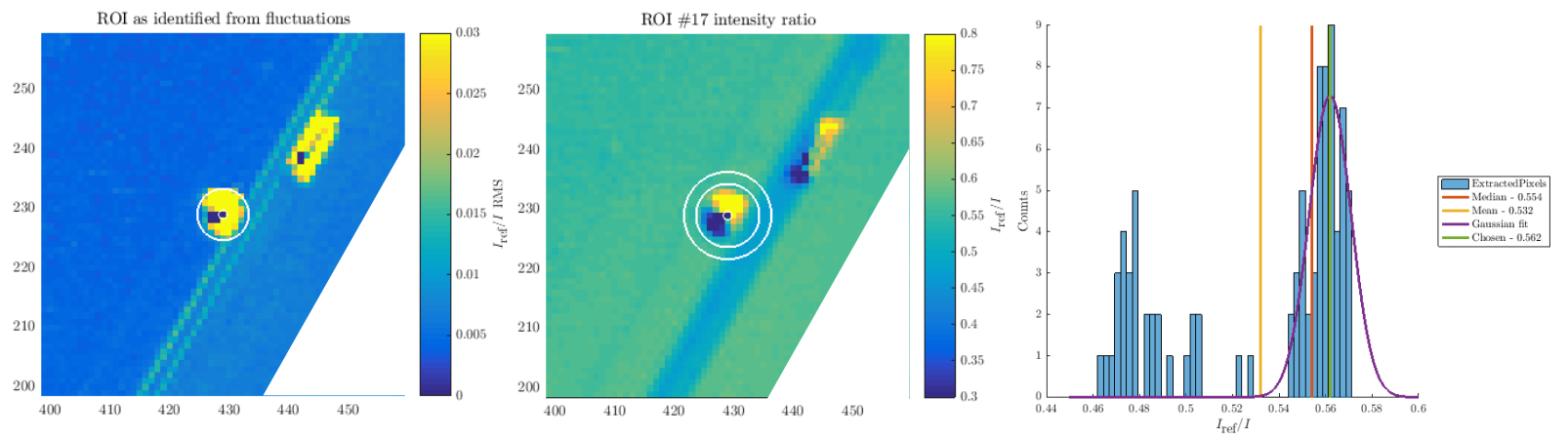

Figure 18: Circle finding, pixel extraction and peak value fitting for determining appropriate transducerequivalent DPSP pressure value.

\section{Dynamic model deformation measurements}

\section{A. Theory \& implementation}

The approach used at ARA to determine the dynamic bending and twisting of model structures is the specklepattern stereoscopic digital image correlation (DIC) technique, mainly provided by the commercial 'StrainMaster' package of LaVision's DaVis software suite complemented by in-house codes to relate the deformations back to customer-prescribed model axes. A pair of cameras are installed to view the surface of interest from two shallow angles and their positions determined by imaging a calibration plate of known geometry (as per Figure 19). A stochastic pattern applied to the surface of interest then allows each region of the model to be identified in both camera views and the pixel location converted into three-dimensional co-ordinates in space (illustrated in Figure 20). Taking images at deformed ('wind-on') and undeformed ('wind-off') conditions allows the displacement at each frame due to aerodynamic loading to be calculated.

Once the system has been installed and calibrated, and wind-on \& wind-off image pairs acquired, they are processed by the StrainMaster program in much the same way as in stereoscopic particle image velocimetry essentially cross-correlating the detected speckle pattern between the frames as if they were seeding particles (Figure 21). The output from StrainMaster is a Cartesian $X / Y$ grid in calibration plate axes where each point has a surface height and a three-component deflection vector. 


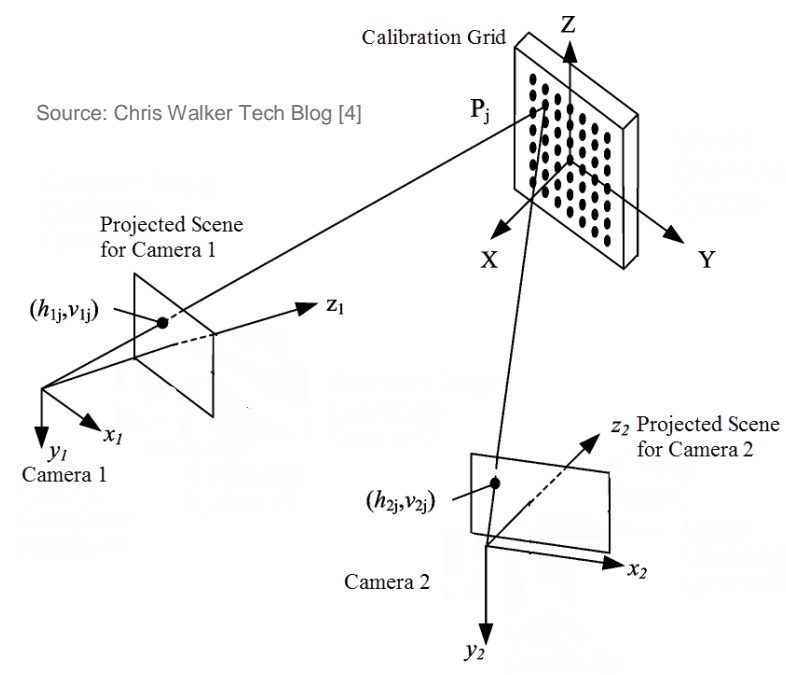

CAMERA CALIBRATION SCHEMATIC
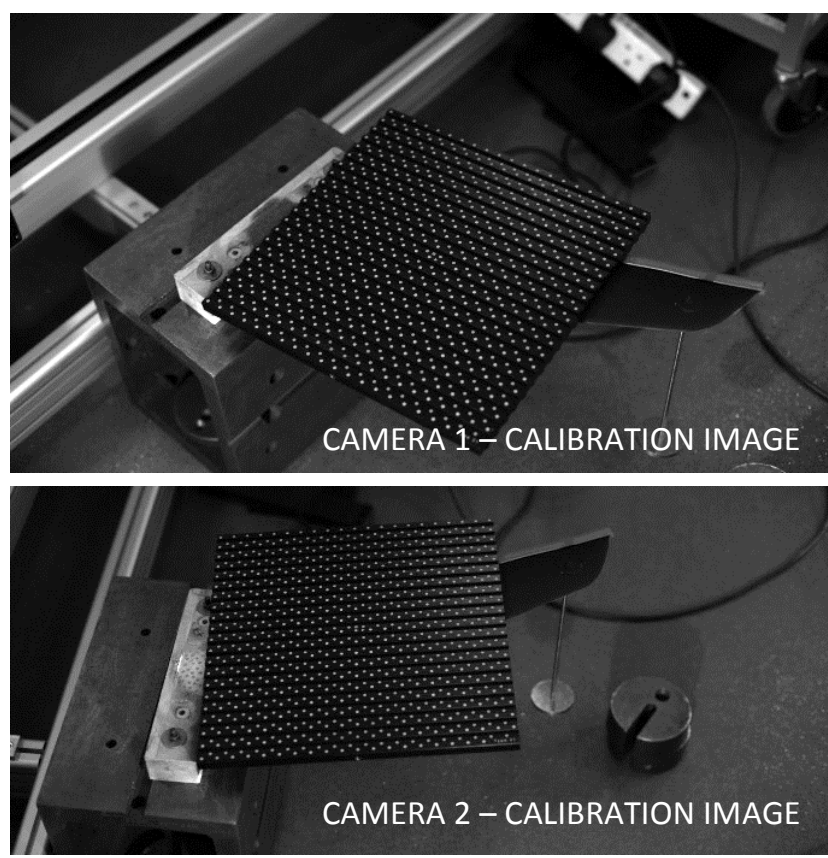

Figure 19: Stereoscopic camera calibration.
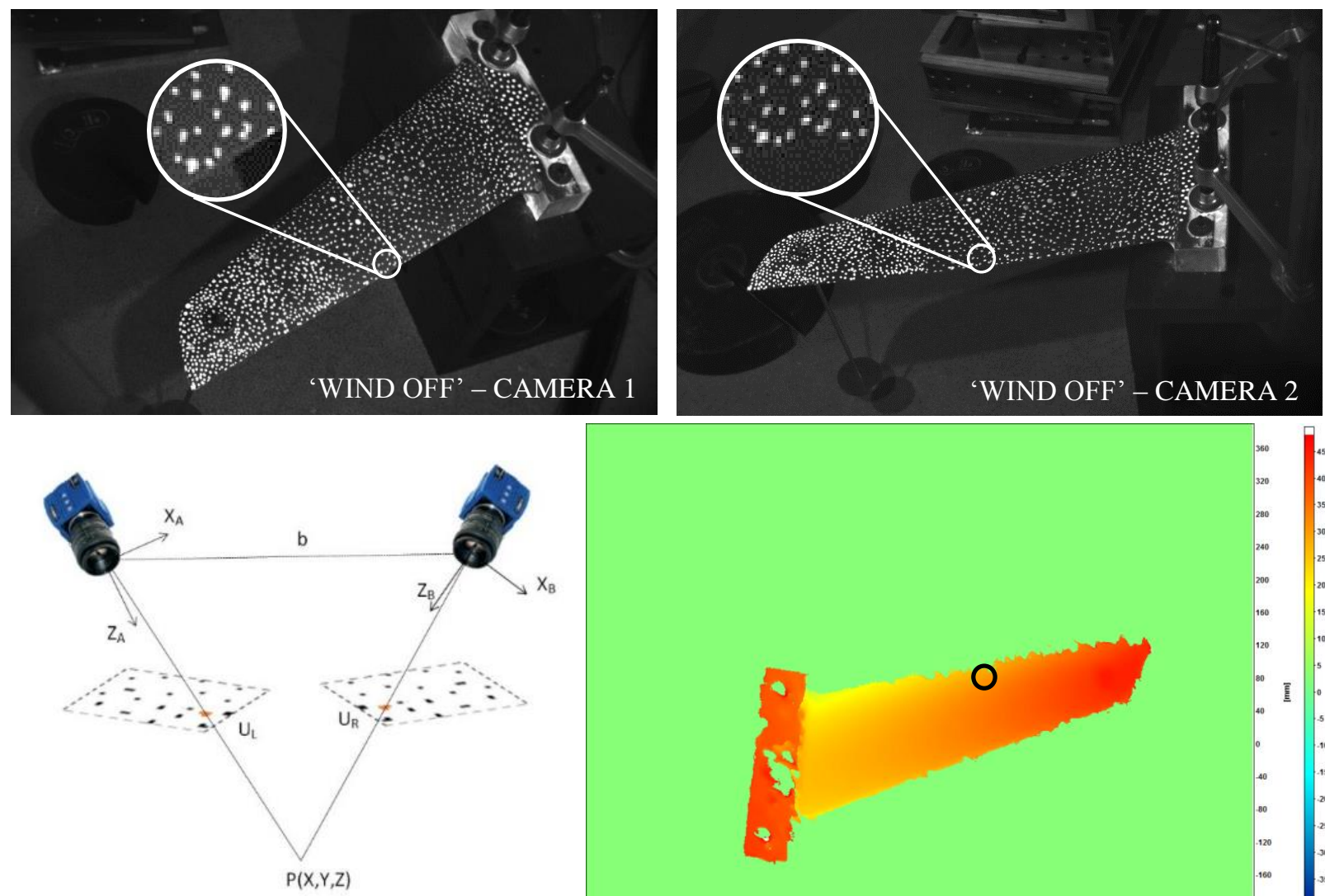

CAMERA SET UP SCHEMATIC

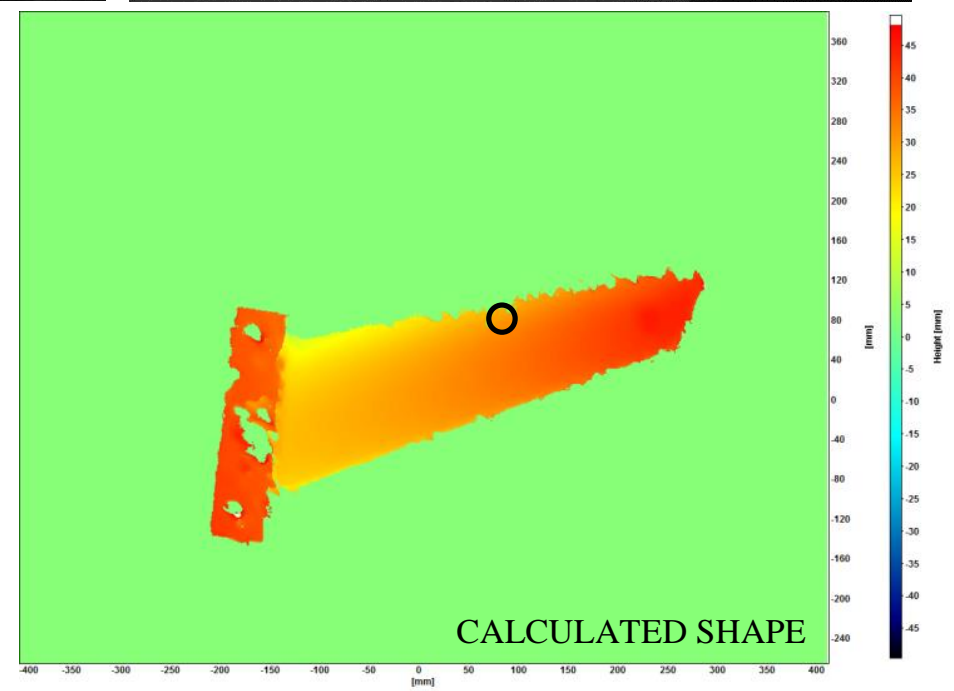

Figure 20: Surface calculation using stereo-vision principles, illustrated with the 'trial wing'. 


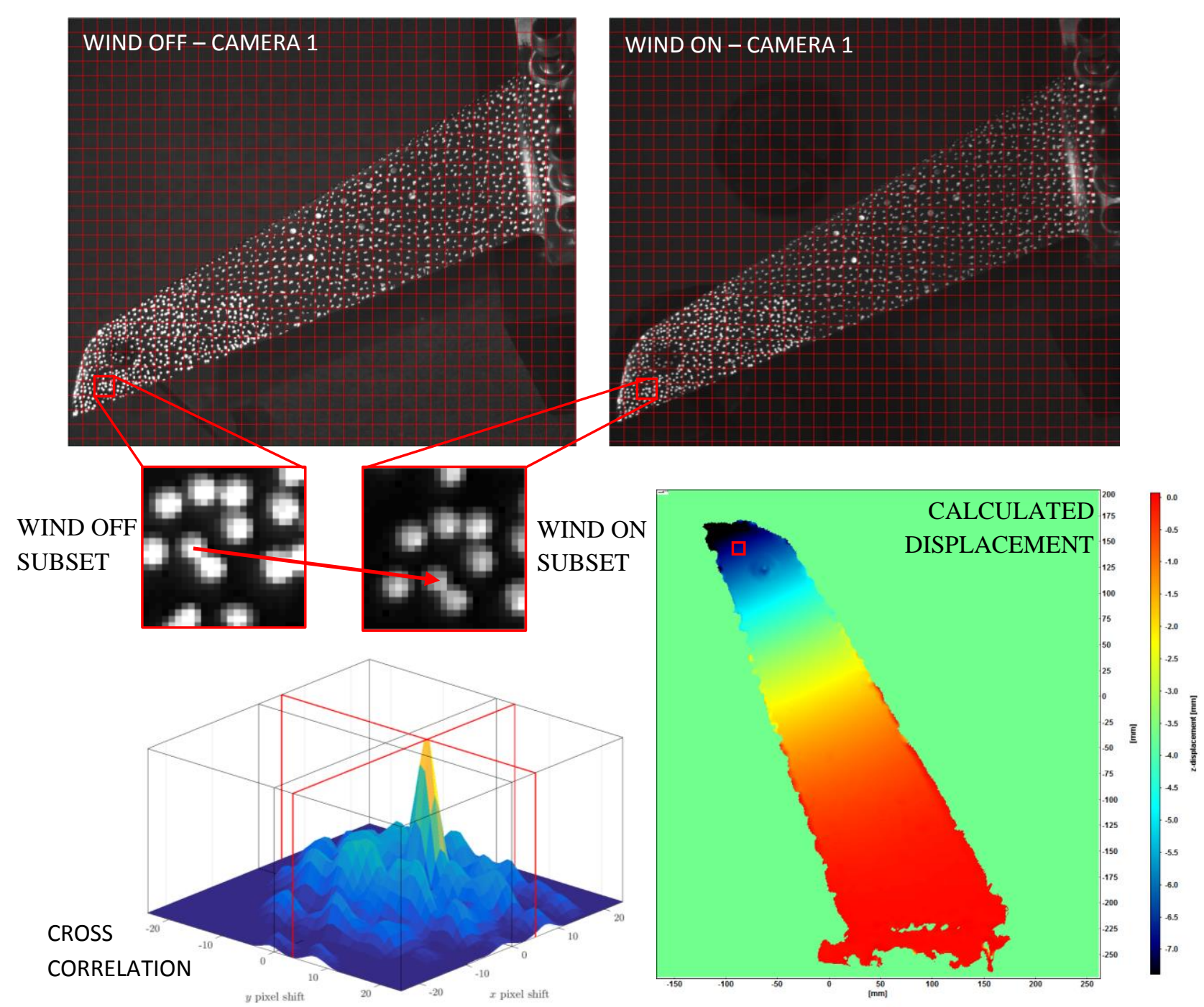

Figure 21: Deflection calculation ('trial wing' with $90 \mathrm{lb}$ point load at tip to simulate wind-on).

LaVision's StrainMaster software does an excellent job of handling the system calibration, acquisition and converting the raw images into surface and deformation data, but to understand the measurements in the context of the model, the results are imported into MATLAB for further post-processing. This stage of the process will be illustrated using images from the gust rig test programme, for which the two Phantom high-speed cameras were installed in the starboard wall. The speckle pattern used for this test was created by applying black marker pen dots directly on top of the DPSP as seen in Figure 3(a). It should be noted that this approach is not viable for simultaneous measurement of pressure and deformation as the marks disrupt the PSP output. However, ARA is investigating the use of projected dots to enable both PSP and MDM data to be collected within the same run with no interference.

Figure 22 shows the surface height grid as loaded into MATLAB. The origin and orientation are defined by the position of the plate in the calibration images, and the extent is set by the mutual field of view of the two cameras. For each point on this grid where a unique pattern can be identified in both camera views, a depth is calculated; elsewhere, a zero value is returned. 

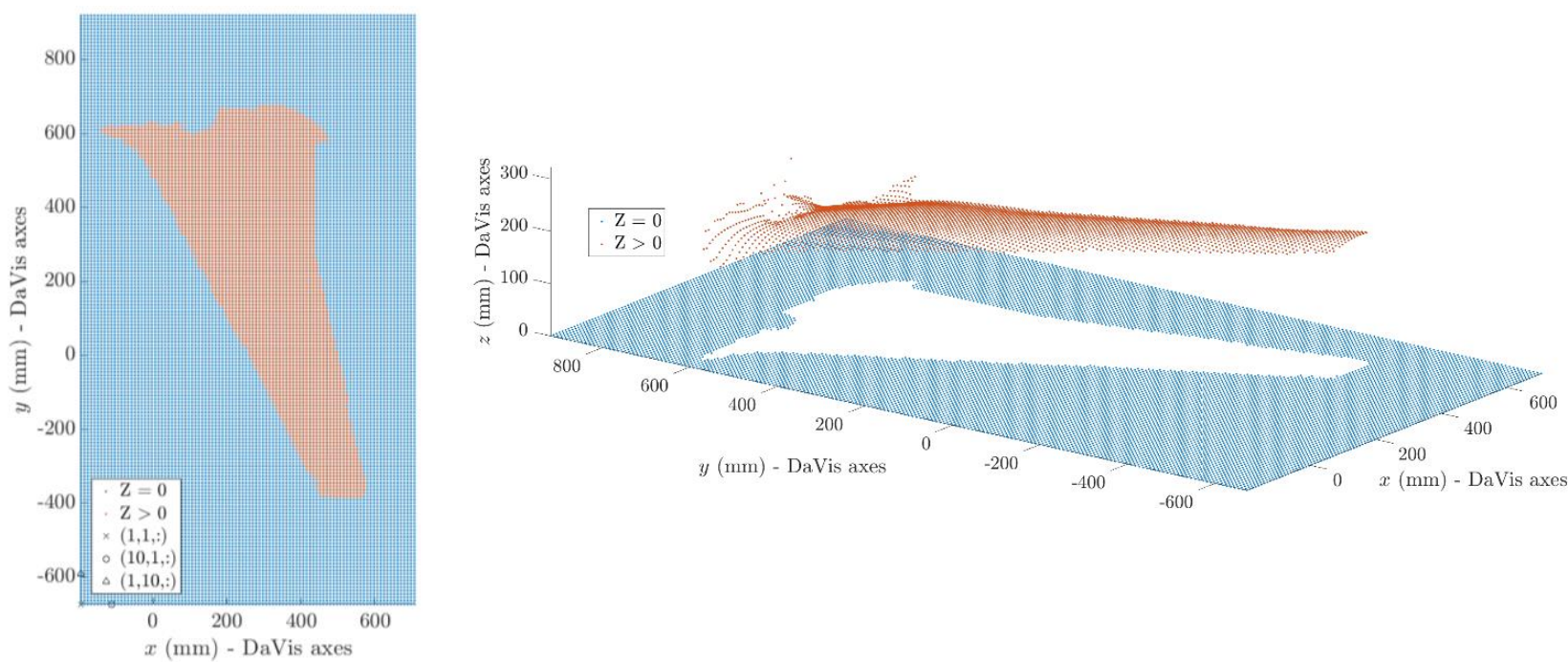

Figure 22: The undeformed Cartesian grid surface height output from Davis as visualised in MATLAB for ARA's civil reference half-model.

In order to understand the measurements in relation to the model, a quasi-Cartesian spanwise/chordwise grid is extracted from CAD with points distributed along the span and chord (Figure 23). The StrainMaster wind-off surface is aligned to this grid through 'point cloud registration', which is performed using the Iterative Closest Point (ICP) technique with a point-to-plane extension. [9] This algorithm is essentially based on a singular value decomposition approach with extra flexibility, as there is no requirement to have the same number of points or distribution across the point cloud fields, and improved robustness due to the iterative process. A 'point-to-plane' enhancement ensures that the evaluation criterion is the distance of the measured points from the known surface normals, as this captures the fact that the MDM grid and CAD grid points will be distributed across the surface in the same manner. The result of the alignment is shown in Figure 24, which also includes the created MDM grid, having been projected/interpolated through from the CAD grid. A similar interpolation is performed on the deflection field for each data point.
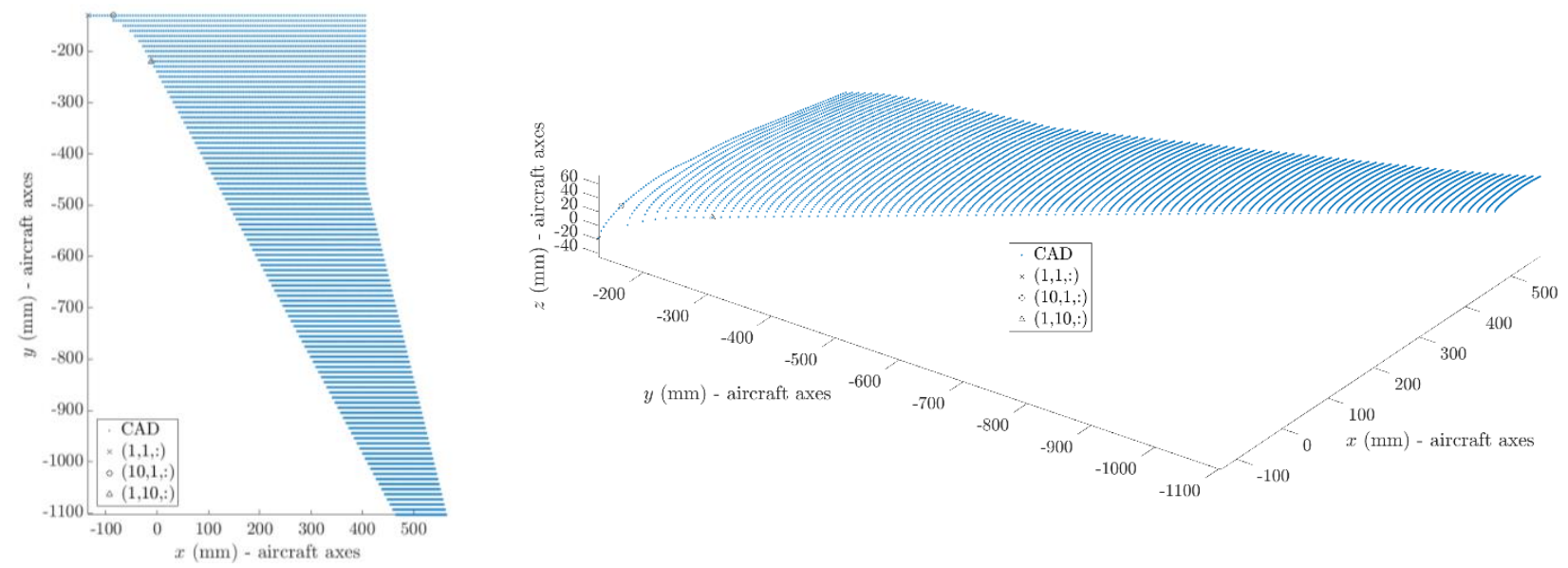

Figure 23: Grid generated from CAD of ARA's reference half-model. 


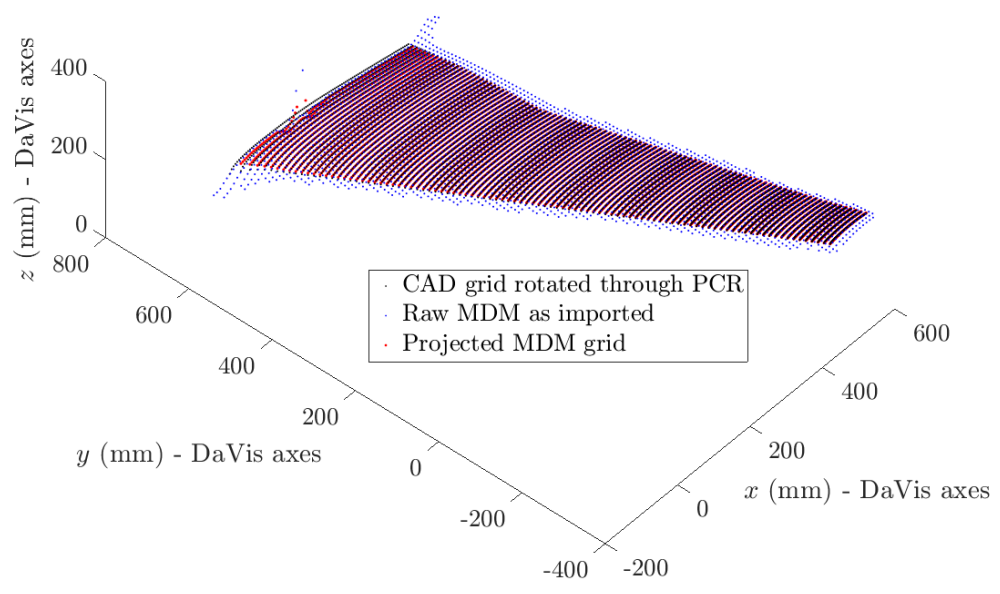

Figure 24: Undeformed surface as obtained by the MDM system registered to CAD grid.

The advantage of referencing the StrainMaster output to a CAD model goes beyond converting the data into aircraft axes - this also enables it to be interrogated using percentages of span and chord, and specific areas to be pre-defined. For example, Figure 25 shows the measured movement at the root of the wing of a full span, sting-mounted model: wind-off to wind-on, such models will move slightly within the tunnel - as the sting bends due to aerodynamic loading, the cart adjusts so that the angle of attack is unchanged, but this creates a translation within the working section. By calculating the movement of the root or fuselage or other region that can be presumed rigid, this bulk motion can be removed from the calculated deflections at each point, leaving only model deformation due to aerodynamic loading.

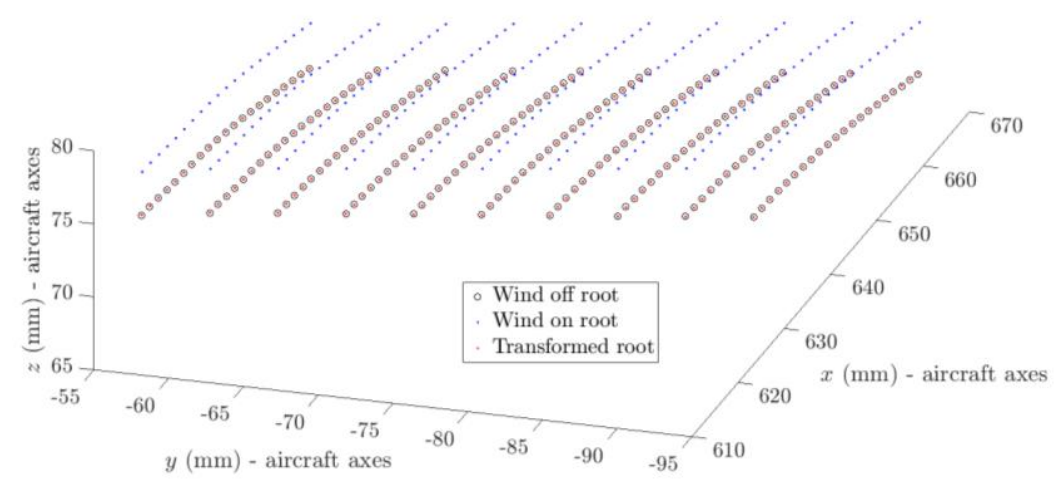

Figure 25: Root movement of a sting-mounted model - the initial wind-off points and deflected wind-on points are shown, as well as the transformed points after calculating and removing the deflection.

Two fitting processes are then applied to the data to reduce the data to more manageable forms: the first is a polynomial along each line of the span (Figure 26) - whose order can be varied depending on the model geometry and the observed trends, with a quartic being the most appropriate for the current test (Figure 27) - and then a linear fit is taken for each chord line (Figure 28). The mean bend for each station is then easily extracted from this second fit along with a twist angle, which are both plotted in Figure 29 along with a summary of the data point in Figure 30. These extracted variables allow easier comparisons between different cases, as shown in Figure 31 where different angles of attack are plotted. The overall accuracy of the DMDM system is analysed in the Appendix, concluding that deformations can be resolved to within $0.1 \mathrm{~mm}$ with a twist accuracy of approximately $0.1^{\circ}$, depending on chord. 

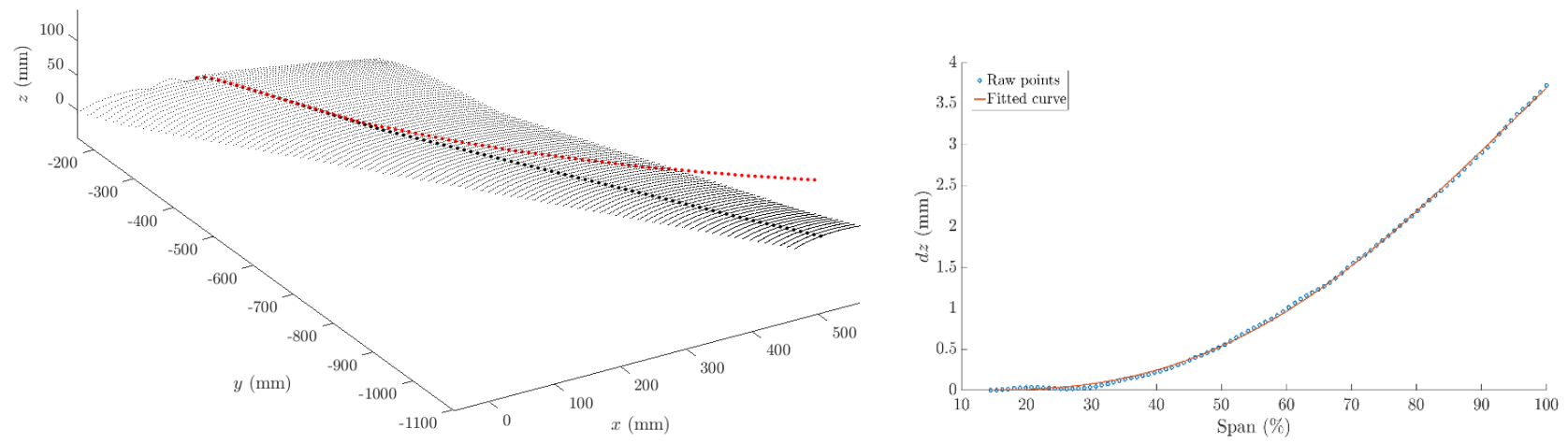

Figure 26: Spanwise line fitting to simplify bend profiles.

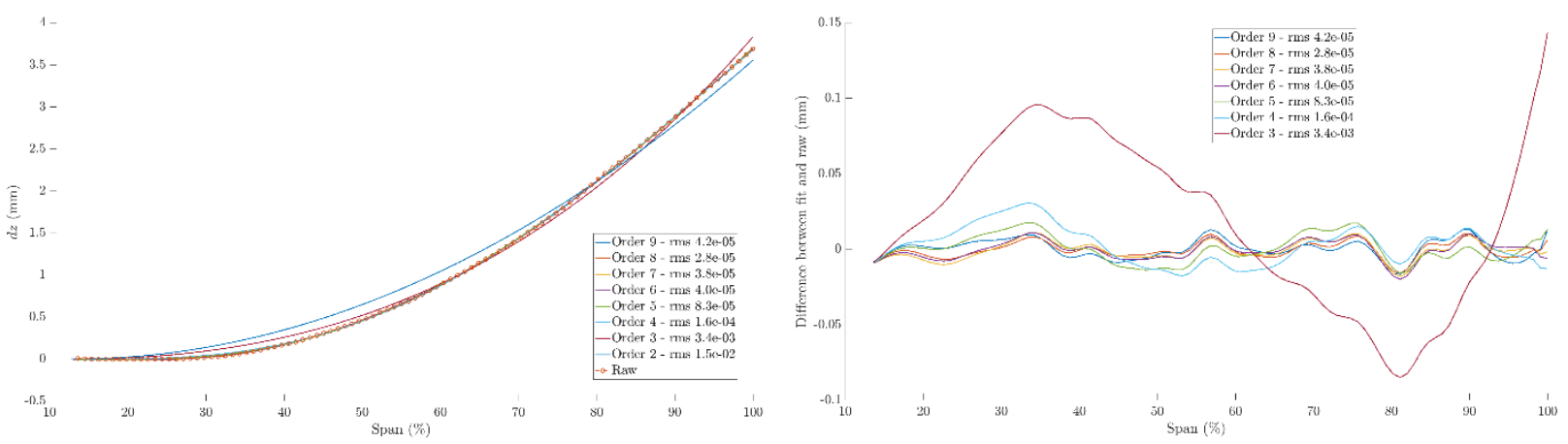

Figure 27: Choosing the polynomial order to fit the bend profiles.
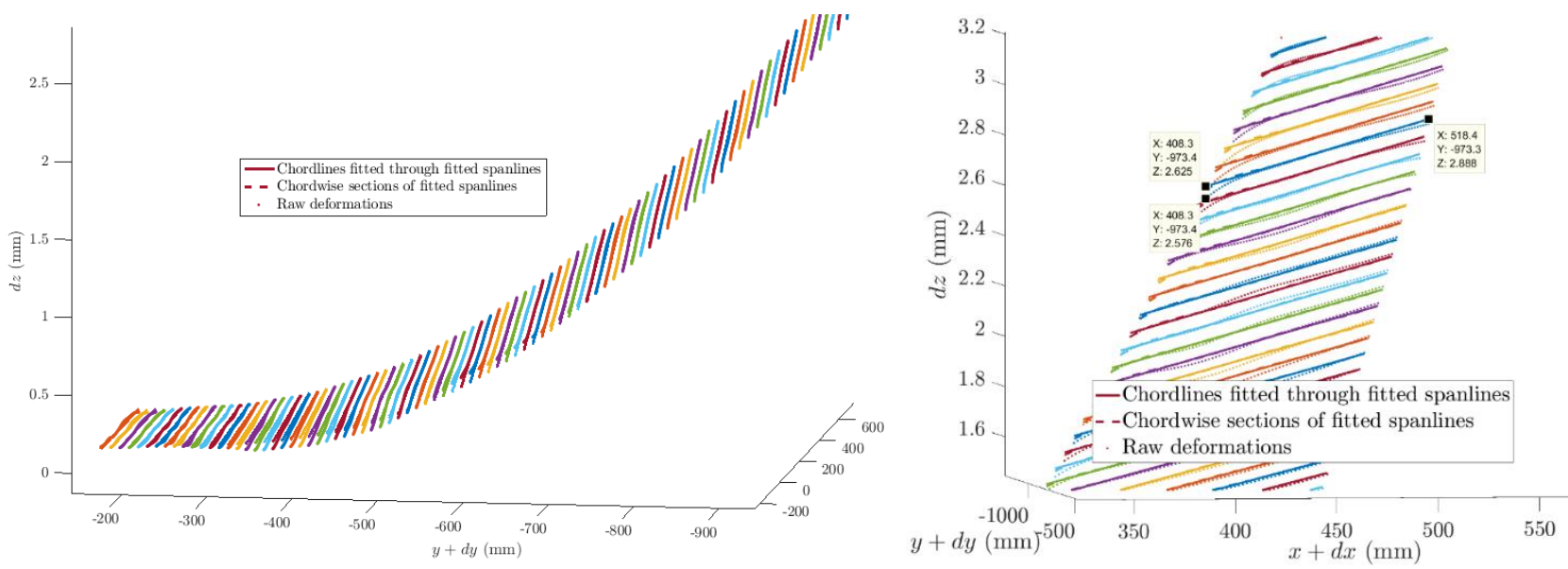

Figure 28: Chord-wise fitted straight lines to obtain sectional twist angles. 

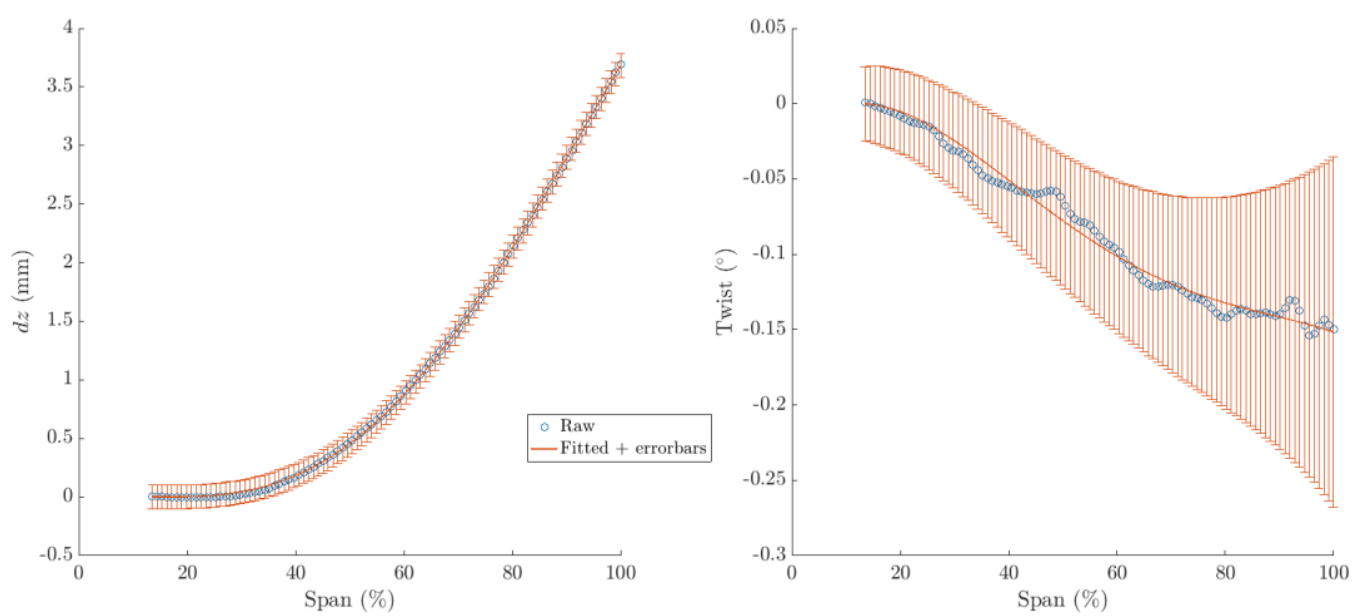

Figure 29: Raw and fitted bend \& twist distributions with error-bars.

\section{B. Results}

Figure 30 presents the mean pre-gust surface deformation contours as well as bend and twist distributions along the span for one data point. To illustrate the performance of the measurement system, Figure 31 collates the mean pregust bending distribution from all data points at a free-stream Mach number of 0.82 and different angles of attack. As different gust profiles were being tested, multiple independent measurements were made at each angle of attack, yet the profiles collapse on to each other within the quoted $0.1 \mathrm{~mm}$ accuracy band.

Figure 32 then shows the mean pre-gust and gust peak deformation contours for a $50 \mathrm{~ms}$ gust carrying a $1^{\circ}$ change in incoming flow incidence. The contours of Figure 33 for a $25 \mathrm{~ms}$ gust are very similar, but the tip trace on the right hand side shows a considerable change - the gust characteristic frequency of $40 \mathrm{~Hz}$ is close enough to excite the model's first bending mode natural frequency of $38 \mathrm{~Hz}$, and so the wing oscillates around its mean bend profile, decaying away over a period of half a second. As seen in the DPSP results though, the peak change due to the gust is greater for the shorter duration, as may be expected - a greater change in the pressure field leads to a greater change in the deformation.
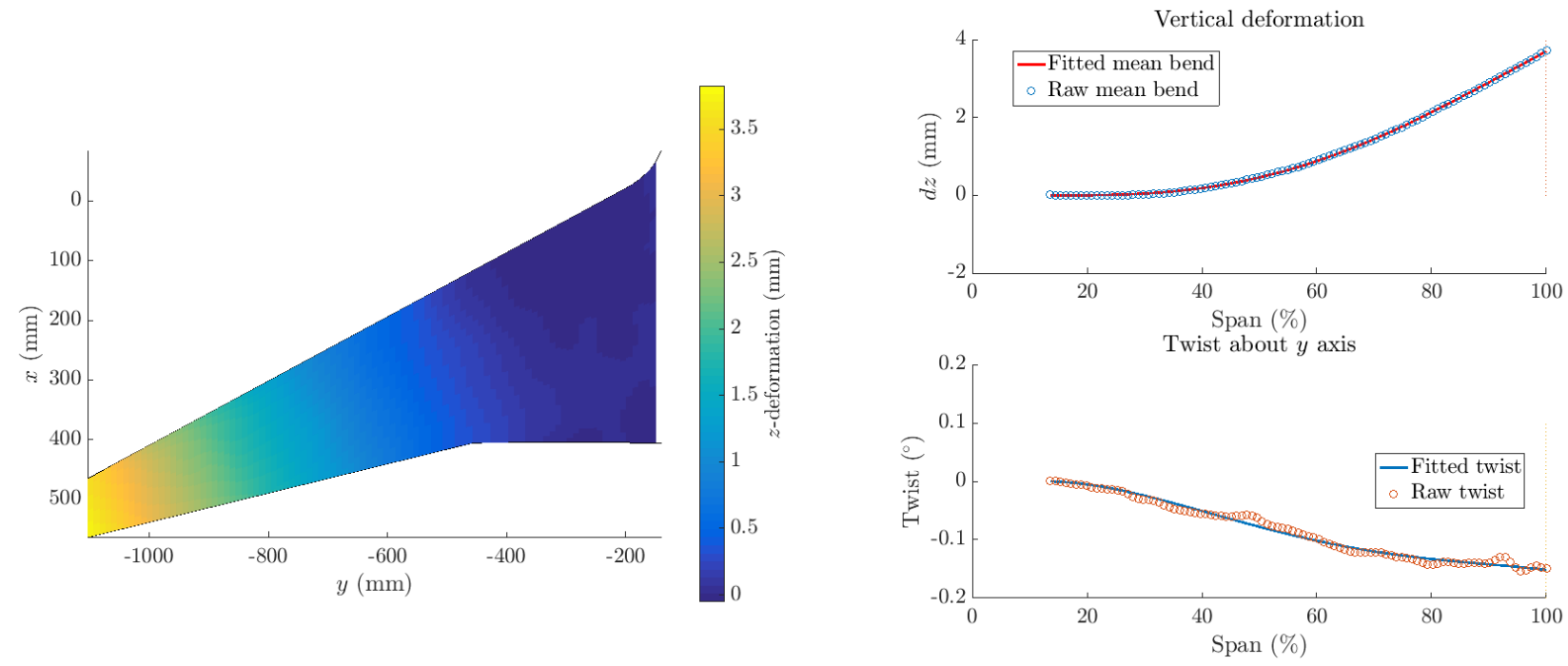

Figure 30: Averaged pre-gust DMDM data point summary. 


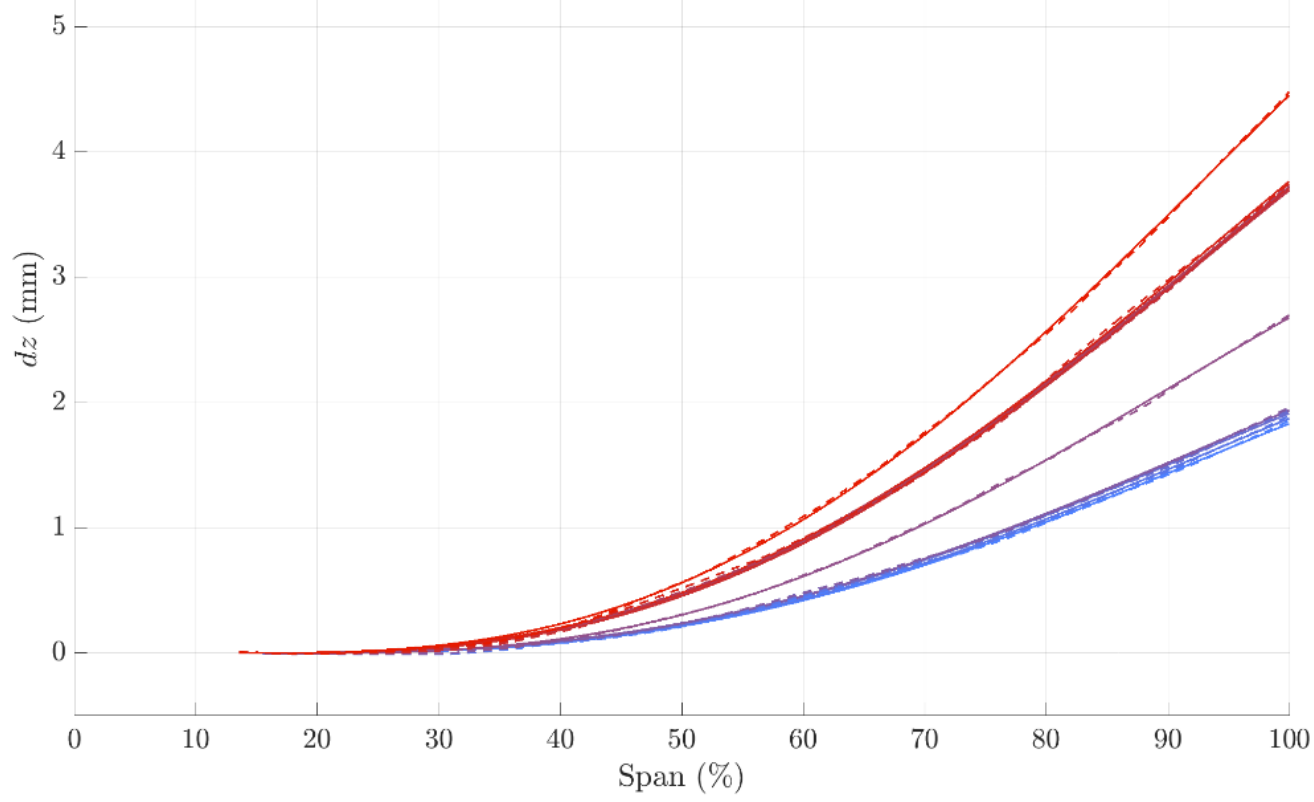

Figure 31: Pre-gust wing bending at Mach 0.82 for $0,0.5,1 \& 1.5^{\circ}$ pitch.
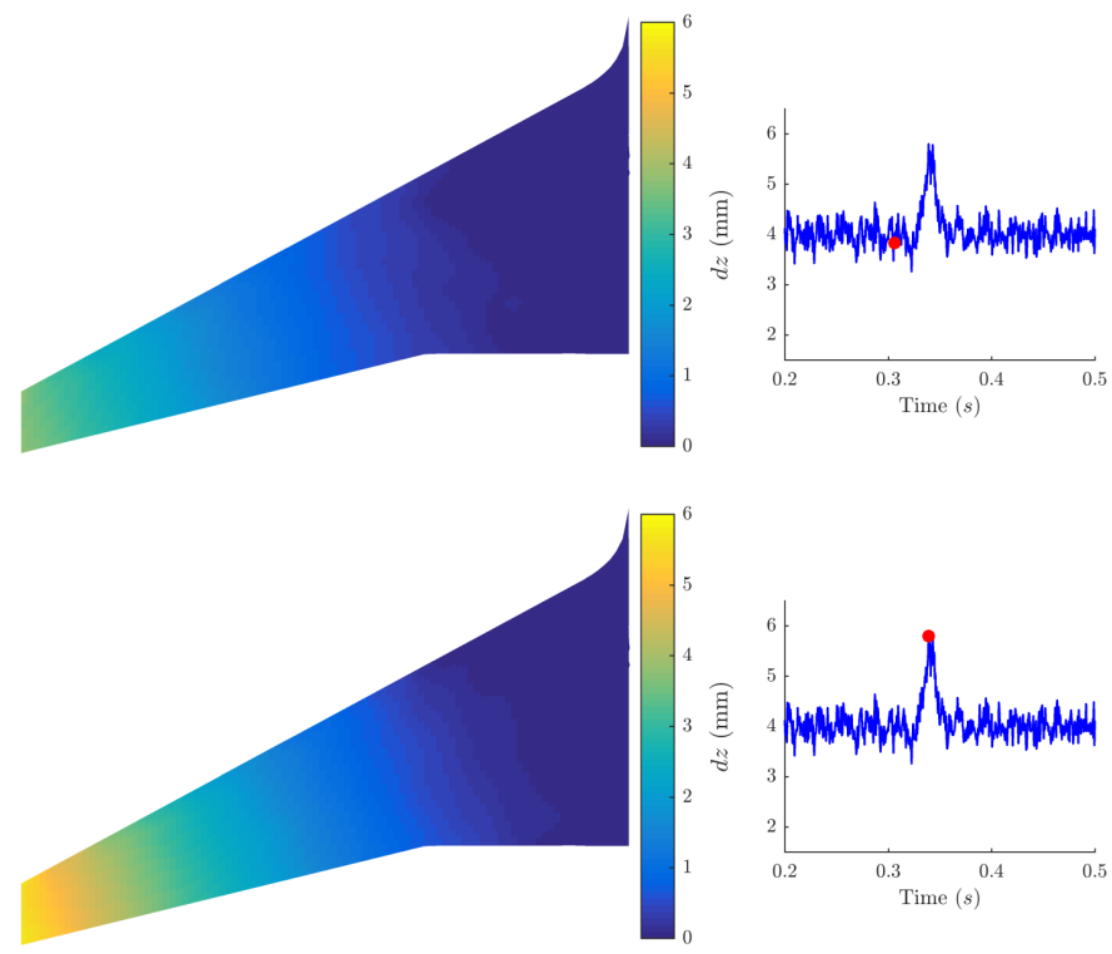

Figure 32: Snapshot images of wing bending and wing tip bending time history for a 50 ms gust at Mach 0.82 - top, pre-gust; bottom, gust peak. 


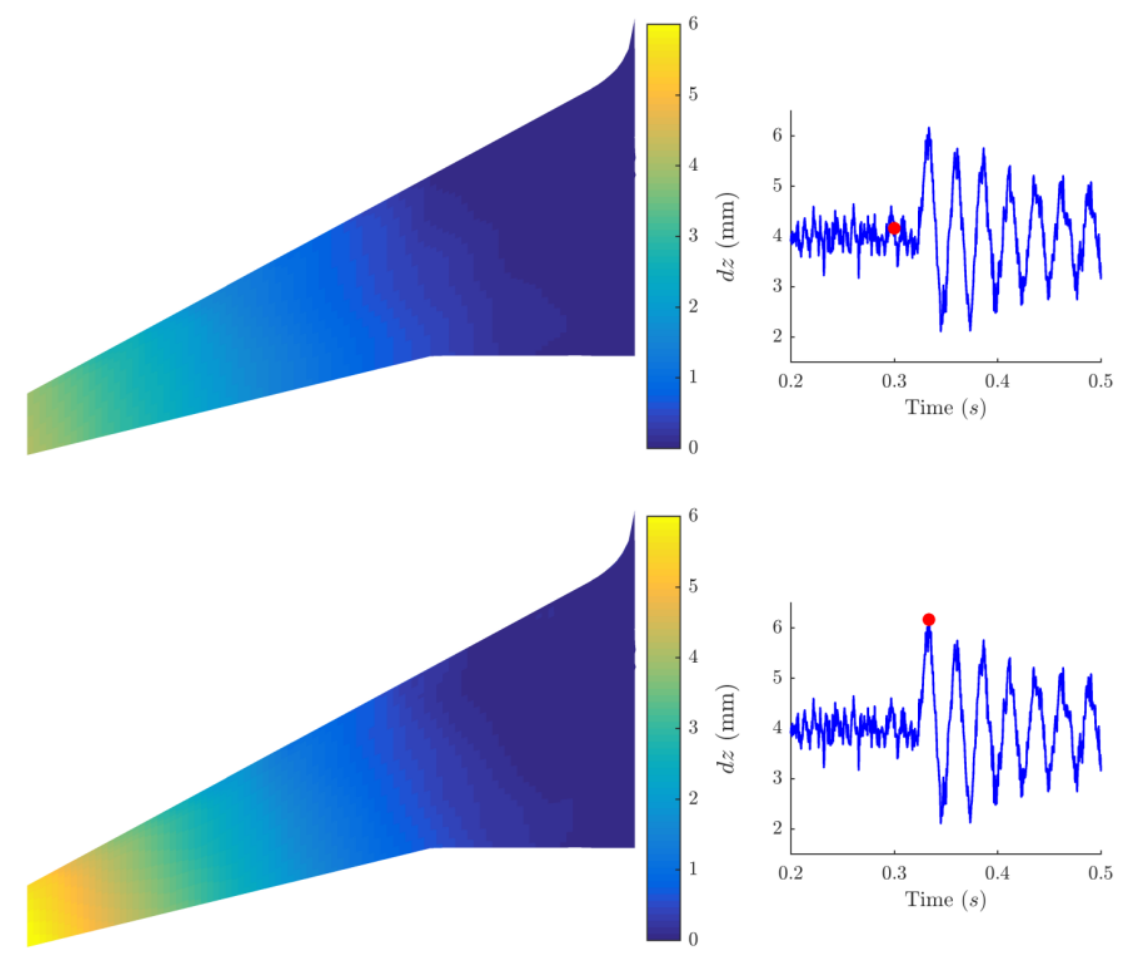

Figure 33: Snapshot images of wing bending and wing tip bending time history for a 25 ms gust at Mach 0.82 - top, pre-gust; bottom, gust peak.

\section{Concluding Remarks}

This test programme has demonstrated the successful use of both Dynamic Pressure-Sensitive Paint and Dynamic Model Deformation Measurements within the commercial Transonic Wind Tunnel at ARA. Both of these techniques are high complex and require expertise and precision for use within a legacy industrial facility. The industrialisation of these methods will now enable customers to understand the unsteady pressure profiles over various model components and also to assess the unsteady deformation characteristics of their models. Both of these activities not only feed in to the validation route for computational modelling, but also provide highly accurate, high coverage data, which would otherwise not be accessible to the industrial customers and researchers. On-going interest and development in these fields will continue to provide innovative opportunities for research at an industrial scale and pace.

\section{Appendix - MDM Measurement Accuracy}

There are two outputs for each measurement of the MDM system. The principle result is the deformation field, but the first output is the wind-off surface shape, which is aligned to a mesh generated from a CAD model before being projected. In order to determine the accuracy of the surface determined through MDM, the root-mean-square discrepancy between the projected points and the CAD points is calculated for each measurement taken. For the civil reference half-model discussed in this paper, which has a semi-span of $1.1 \mathrm{~m}$, the MDM surface-to-CAD r.m.s. discrepancy varied between 0.50 and $1.09 \mathrm{~mm}$, with a mean of $0.75 \mathrm{~mm}$, or $0.07 \%$ of the field-of-view (with the majority of the error coming from a small region near the root due to a poor speckle pattern). On another test, with an aircraft semi-span of $0.49 \mathrm{~m}$, the discrepancy was $0.30 \mathrm{~mm}$, or similarly small at $0.06 \%$, ensuring that we can accurately resolve model shape and identify where deformations are occurring.

An experiment was conducted using the 'trial wing' seen in Figure 19 to determine the accuracy of the deformations measured by the MDM system. Weights of up to $90 \mathrm{lb}$ were applied to the wing tip while the model was securely bolted to a platform, itself bolted to the floor (Figure 21). Measurements of the deflection were taken at a number of discrete locations around the wing using a dial clock with a resolution of $10 \mu \mathrm{m}$, and of the full surface through MDM with an experimental set-up emulating the distances and positioning of a typical test in the ARA TWT. The appropriate regions were extracted for the surface data and a comparison shown in Figure 34. The peak 
discrepancy observed was $0.11 \mathrm{~mm}$, with a root-mean-square deviation of $0.04 \mathrm{~mm}$, confirming that the technique is able to provide reliable measurements of the model deformation. For a typical model chord of $100 \mathrm{~mm}$, this equates to an accuracy of $0.1^{\circ}$ for determining wing twist.

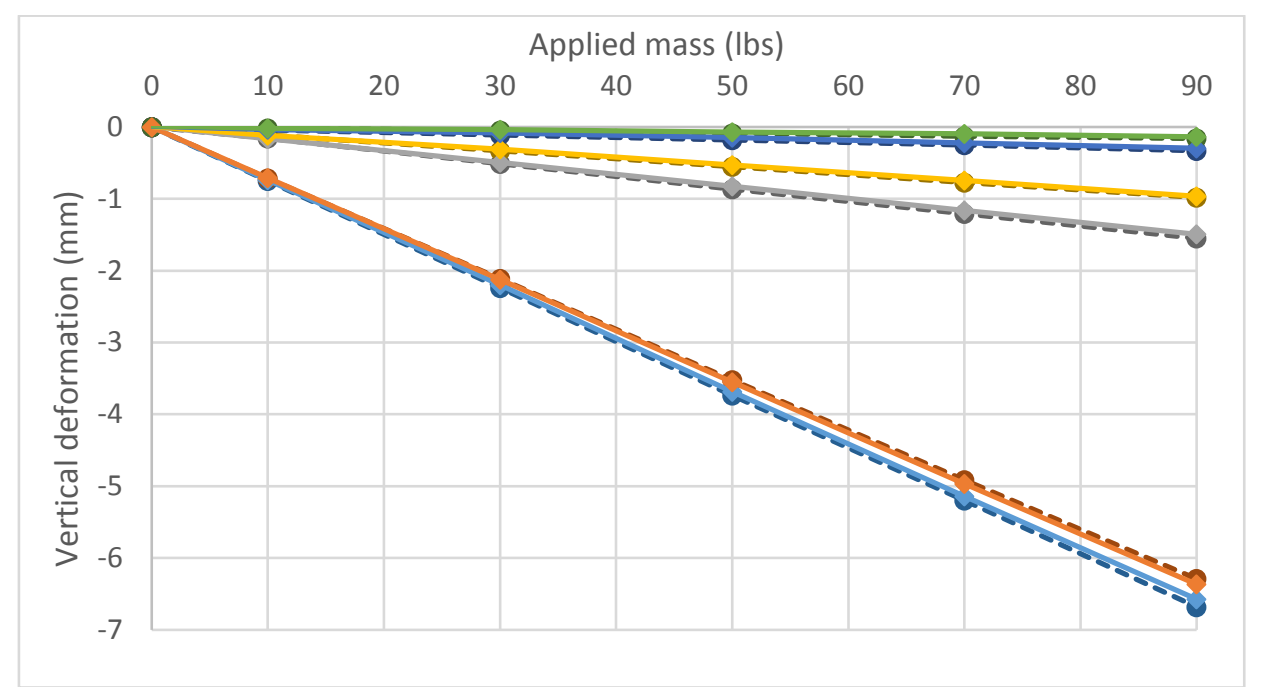

Figure 34: Comparison between dial clock (dashed) and MDM (solid) measurements for six positions on the trial wing upper surface.

Acknowledgements

The support of Innovate UK and the UK Aerospace Technology Institute (ATI) is acknowledged in funding the work described in this paper, through both the ARCADE (Aerodynamic Research testing and CApability Data Enhancement) and the EFT (Enhanced Fidelity Transonic wing) projects. The first author is funded by Innovate UK through the Knowledge Transfer Network as a Knowledge Transfer Partnership Associate at the University of Manchester.

\section{References}

[1] B. Millard, E. Vardaki and N. Stokes, "ARA EA Tech Note 2010/10: Results from investigations into PSP and drag data," 2010.

[2] N. J. Allen and M. K. Quinn, "Development of a Transonic Gust Rig for Simulation of Vertical Gusts on Halfmodels," in 31st AIAA Aerodynamic Measurement Technology and Ground Testing Conference, AIAA AVIATION Forum, Dallas, TX, 2015.

[3] A. Gomariz-Sanchez, D. A. Roberts, A. Peace and T. S. C. Davidson, "Towards the industrialisation of a transonic gust rig for simulation of gusts on half-models," in 2018 AIAA Aerospace Sciences Meeting, AIAA SciTech Forum, Kissimmee, FL, 2018.

[4] D. A. Roberts, N. P. Stokes, M. K. Quinn, J. Coppin and T. J. Birch, "Evaluation of Dynamic Pressure-Sensitive Paint for Improved Analysis of Cavity Flows and CFD Validation," in 54th AIAA Aerospace Sciences Meeting, AIAA SciTech, San Diego, CA, 2016.

[5] W. Flaherty, T. M. Reedy, G. S. Elliott, J. M. Austin, R. F. Schmit and J. Crafton, "Investigation of Cavity Flow Using Fast-Response Pressure-Sensitive Paint," AIAA Journal, vol. 52, no. 11, pp. 2462-2470, 2014.

[6] M. Quinn, L. Yang and K. Kontis, "Pressure-Sensitive Paint: Effect of Substrate," Sensors, vol. 11, no. 12, pp. 11649-11663, 2011. 
[7] E. Vardaki, N. P. Stokes, S. Patel and P. Gustafsson, "Pressure Sensitive Paint Measurements on the Gripen Model at the ARA Transonic Wind Tunnel," in 50th AIAA Aerospace Sciences Meeting, AIAA SciTech, Nashville, TN, 2012.

[8] S. Lawson, D. Greenwell and M. K. Quinn, "Characterisation of Buffet on a Civil Aircraft Wing," in 54th AIAA Aerospace Sciences Meeting, AIAA SciTech, San Diego, CA, 2016.

[9] H. M. Kjer and J. Wilm, "Evaluation of surface registration algorithms for PET motion correction," BSc Thesis, Technical University of Denmark, 2010.

[10] L. Masini, S. Timme and A. Peace, "Experimental Transonic Shock Buffet Study on a Civil Aircraft Wing," in DiPaRT Flight Physics Symposium, Bristol, UK, 2017. 